\title{
Systemic Neutrophil Depletion Modulates the Migration and Fate of Transplanted Human Neural Stem Cells to Rescue Functional Repair
}

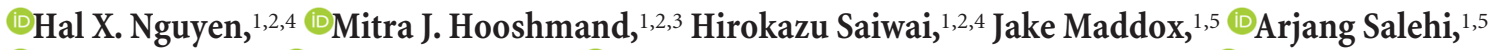 \\ (DAnita Lakatos, ${ }^{1,2}$ @Rebecca A. Nishi, ${ }^{2}$-Desiree Salazar, ${ }^{2,3,4}$ Nobuko Uchida, ${ }^{6}$ and ${ }^{-1}$ Aileen J. Anderson ${ }^{1,2,3,4}$ \\ ${ }^{1}$ Sue and Bill Gross Stem Cell Research Center, ${ }^{2}$ Institute for Memory Impairments and Neurological Disorders, and Departments of ${ }^{3} \mathrm{Anatomy}$ and \\ Neurobiology, ${ }^{4}$ Physical Medicine and Rehabilitation, and ${ }^{5}$ Molecular Biology and Biochemistry, University of California, Irvine, Irvine, California 92697 , \\ and ${ }^{6}$ StemCells, Inc., Palo Alto, California 94304
}

The interaction of transplanted stem cells with local cellular and molecular cues in the host CNS microenvironment may affect the potential for repair by therapeutic cell populations. In this regard, spinal cord injury (SCI), Alzheimer's disease, and other neurological injuries and diseases all exhibit dramatic and dynamic changes to the host microenvironment over time. Previously, we reported that delayed transplantation of human CNS-derived neural stem cells (hCNS-SCns) at 9 or $30 \mathrm{~d}$ post-SCI (dpi) resulted in extensive donor cell migration, predominantly neuronal and oligodendrocytic donor cell differentiation, and functional locomotor improvements. Here, we report that acute transplantation of hCNS-SCns at 0 dpi resulted in localized astroglial differentiation of donor cells near the lesion epicenter and failure to produce functional improvement in an all-female immunodeficient mouse model. Critically, specific immunodepletion of neutrophils (polymorphonuclear leukocytes) blocked hCNS-SCns astroglial differentiation near the lesion epicenter and rescued the capacity of these cells to restore function. These data represent novel evidence that a host immune cell population can block the potential for functional repair derived from a therapeutic donor cell population, and support targeting the inflammatory microenvironment in combination with cell transplantation after SCI.

Key words: cell therapy; functional repair; immunotherapy; neuroinflammation; neutrophils; spinal cord injury

Significance Statement

The interaction of transplanted cells with local cellular and molecular cues in the host microenvironment is a key variable that may shape the translation of neurotransplantation research to the clinical spinal cord injury (SCI) human population, and few studies have investigated these events. We show that the specific immunodepletion of polymorphonuclear leukocyte neutrophils using anti-Ly6G inhibits donor cell astrogliosis and rescues the capacity of a donor cell population to promote locomotor improvement after SCI. Critically, our data demonstrate novel evidence that a specific host immune cell population can block the potential for functional repair derived from a therapeutic donor cell population.

\section{Introduction}

The interaction of transplanted cell populations with local cellular and molecular cues in the host microenvironment is a key

Received Sept. 1, 2016; revised June 15, 2017; accepted July 30, 2017.

Author contributions:H.X.N., M.J.H., and A.J.A. designed research;H.X.N., M.J.H., H.S., J.M., A.S., R.A.N., and D.S. performed research; N.U. contributed unpublished reagents/analytic tools; H.X.N., M.J.H., H.S., J.M., A.S., A.L., and R.A.N. analyzed data; H.X.N., M.J.H., and A.J.A. wrote the paper.

This study was funded by National Institutes of Health (NIH) Grant NS-49885 (to A.J.A.), California Institute for Regenerative Medicine (CIRM) Grant RB2-01496 (to H.X.N. and A.J.A.), Paralysis Project of America Grant PPA-32574 (to H.X.N.), CIRM Stem Cell Training Award T1-00008 (to H.X.N.), Christopher and Dana Reeve Foundation Grant CRF-AAC 2005 (to A.J.A.), National Center for Research Resources and the National Center for Advancing Translational Sciences (NIH) Grant UL1-TR-001414), The Morton Cure Paralysis Fund MCPF-204464 (to H.X.N.), and StemCells, Inc. We thank the technical staff at the Christopher and Dana Reeve Foundation Animal Injury Core: Hongli Liu and Jovanny Lucero, as well as Gabriella Funes, Joel Trushinsky, and Dena Yassin. variable that remains to be elucidated and may shape the translational application of therapeutic cell populations for a clinical spinal cord injury (SCI) population. A principle factor altering the molecular and cellular composition of the host niche is time after injury, which is in part characterized by the recruitment of inflammatory mediators in distinct stages and distributions beginning at the acute $[<7 \mathrm{~d}$ post-SCI $(\mathrm{dpi})]$ and persisting through

N.U. has a financial interest in StemCells, Inc. The authors declare no other competing financial interests. Correspondence should be addressed to either of the following: Hal X. Nguyen, 2101 Sue and Bill Gross Hall, University of California, Irvine, Irvine, CA 92697, E-mail: hnguyen@uci.edu; or Aileen J. Anderson, 2026 Sue and Bill Gross Hall, University of California, Irvine, Irvine, CA 92697, E-mail: aja@uci.edu.

DOI:10.1523/JNEUROSCI.2785-16.2017

Copyright $\odot 2017$ the authors $\quad 0270-6474 / 17 / 379269-19 \$ 15.00 / 0$ 
the subacute ( $7-14 \mathrm{dpi})$ and chronic ( $>14 \mathrm{dpi}$ ) phases of trauma (Popovich et al., 1997; Jones et al., 2005; Fleming et al., 2006; Kigerl et al., 2006; Beck et al., 2010). In particular, a multiphasic cellular response has been identified in a rodent SCI model that includes an early neutrophil [polymorphonuclear leukocytes (PMNs) at $1 \mathrm{dpi}$ infiltration, and a biphasic microglia/macrophage (7 and 60 dpi) response (Beck et al., 2010; Nguyen et al., 2011) Accumulating evidence supporting a dual role for infiltrating immune cells has suggested both detrimental (Popovich et al., 1999; Weaver et al., 2000; Jones et al., 2005) and beneficial (Beck et al., 2010; Rapalino et al., 1998; Schwartz and Yoles 2005; David and Kroner, 2011) effects on regeneration and repair after SCI.

A number of studies have suggested that inflammatory cytokines can modulate neural stem cell (NSC) proliferation and differentiation in vitro (Butovsky et al., 2006; Kokaia et al., 2012). In parallel, microglia have been shown to induce migration and/or enhance neural lineage selection in mouse neural progenitors in vitro (Aarum et al., 2003) and in endogenous hippocampal progenitors in vivo (Monje et al., 2003). However, the effect of modulation of the inflammatory or immune microenvironment on the migration, differentiation, or therapeutic efficacy of a transplanted cell population has not previously been tested. Critically, the studies presented here are thus unique, demonstrating novel evidence that a host immune cell population blocks the potential for functional repair derived from a transplanted therapeutic cell population.

In the present study, we used human CNS-derived NSCs (hCNS-SCns) propagated as neurospheres (Uchida et al., 2000), which are capable of differentiation into human neurons, oligodendrocytes, and astrocytes in vitro and in vivo (Tamaki et al., 2002), and retain multipotency for $>20$ passages. We investigated the survival and engraftment of hCNS-SCns in animals receiving transplants acutely $(0 \mathrm{dpi})$ after $\mathrm{SCI}$ and compared these results relative to animals transplanted at a delayed time of $30 \mathrm{dpi}$ in an otherwise identical paradigm. Contrary to conventional predictions (Nakamura and Okano 2013), the results demonstrated comparable engraftment of transplanted cells at both time points. However, in comparison with delayed transplants, animals receiving hCNS-SCns at 0 dpi exhibited a clear shift in donor cell localization at the injury epicenter, which was associated with a striking increase in astroglial lineage selection, and failure to exhibit recovery of function. Because the acute injury microenvironment is associated with robust activation of the innate inflammatory response, including transient early accumulation of PMNs at the lesion epicenter (Beck et al., 2010), we next investigated whether specific PMN depletion could alter the fate and migration of transplanted hCNS-SCns and restore the potential for donor cells to improve locomotor function. We demonstrate that PMN depletion via anti-Ly6G treatment was specific and sustained and resulted in the release of donor human cell localization to the injury epicenter, the inhibition of human astrocyte differentiation, and the rescue of the capacity of transplanted hCNS-SCns to improve locomotor recovery. Together, these data demonstrate a potential therapeutic strategy to modulate the host CNS microenvironment and promote functional repair by a donor cell population.

\section{Materials and Methods}

Exclusions, final numbers, and experimental blinding. All surgical, behavioral, histological, and quantitative analyses were performed by observers blinded to groups. Preinjury and postinjury animal exclusions, Grubbs test exclusions, and final animal numbers for statistical analysis are detailed below. There were no animal exclusions due to engraftment failure or at the stage of histological analysis. The number of animals that received SCI and cell transplant and the number of animals that were used

\section{Table 1. Number of animals}

\begin{tabular}{|c|c|c|c|}
\hline & Vehicle $(N)$ & Acute $\operatorname{Tx}(N)$ & Delayed Tx $(N)$ \\
\hline \multicolumn{4}{|l|}{ Acute vs delayed Tx } \\
\hline SCl and cell Tx & 16 & 16 & 16 \\
\hline SC121 human cell stereology & $\mathrm{N} / \mathrm{A}$ & 6 & 6 \\
\hline SC123 human astrocyte stereology & $\mathrm{N} / \mathrm{A}$ & 6 & N/A \\
\hline Fibronectin lesion volume & 6 & 6 & N/A \\
\hline \multirow[t]{2}{*}{ CatWalk gait analysis } & 16 & 15 & $\mathrm{~N} / \mathrm{A}$ \\
\hline & $\lg G 2 a(N)$ & \multicolumn{2}{|c|}{ Anti-Ly6G $(N)$} \\
\hline \multicolumn{4}{|l|}{ PMN depletion study } \\
\hline $\mathrm{SCl}$ only & 8 & 8 & \\
\hline \multicolumn{4}{|l|}{ Acute Tx } \\
\hline SCl and cell Tx & 12 & 12 & \\
\hline Fibronectin lesion volume & 5 & 5 & \\
\hline SC121 human cell stereology & 5 & 5 & \\
\hline SC123 human astrocyte stereology & 5 & 5 & \\
\hline SC121 cluster volume & 5 & 5 & \\
\hline SC123 cluster volume & 5 & 5 & \\
\hline CatWalk gait analysis & 10 & 10 & \\
\hline Hargreaves & 10 & 10 & \\
\hline \multicolumn{4}{|l|}{ Vehicle } \\
\hline $\mathrm{SCl}$ and vehicle injection & 12 & 12 & \\
\hline CatWalk gait analysis & 12 & 10 & \\
\hline Hargreaves & 12 & 10 & \\
\hline
\end{tabular}

Tx, Transplantation.

for stereological analysis and behavioral assessments for all experiments are summarized in Table 1 .

\section{Acute versus delayed cell transplantation studies}

Contusion SCI and cell transplantation. Female NOD-scid mice $(N=$ 16/group, 10 weeks old; The Jackson Laboratory) were anesthetized using Avertin $(0.5 \mathrm{ml} / 20 \mathrm{~g}$ tribromo-ethanol) and received a laminectomy at the thoracic vertebrae 9 (T9) using a surgical microscope. The animals were secured in a spinal stereotactic apparatus to receive 50 kilodyn $(1 \mathrm{dyn}=10 \mu \mathrm{N})$ contusion injuries using the Infinite Horizon (IH) Impactor (Precision Systems and Instrumentation) at T9. Before SCI, animals were randomly assigned to receive either hCNS-SCns or vehicle injections. A priori exclusion criteria were as follows: evidence of cord bruising during laminectomy, less than $\pm 10 \%$ of 50 kilodyn force based on force/ displacement curve, or evidence of unilateral cord bruising after SCI. Exclusion of animals was determined by investigators blinded to groups.

hCNS-SCns were provided by StemCells and are derived via fluorescence-activated cell sorting from donated fetal brain tissue and expanded as neurospheres based on expression of the stem cell marker $\mathrm{CD} 133^{+}$, lack of the hematopoietic markers CD $34^{-}$and $\mathrm{CD} 45^{-}$, and low levels of $\mathrm{CD} 24^{\mathrm{lo}}$. Sorting by these markers has previously been shown to result in a highly enriched population of human NSCs (hNSCs), and the development and transplantation of these cells has been described in detail previously (Uchida et al., 2000). Polished siliconized beveled glass pipettes (bevel: inner diameter, $70 \mu \mathrm{m}$; outer diameter, 100-110 $\mu \mathrm{m}$; Sutter Instruments) were loaded with freshly triturated Passage 9-10 multipotent hCNS-SCns (75,000 cells/ $\mu$ l injection buffer) or vehicle injection buffer (50\% X-Vivo, 50\% HBSS), which were injected into the intact parenchyma at T9 using a NanoInjector system and micropositioner (WPI Instruments). Each site received $250 \mathrm{nl}$ of cells or vehicle, delivered in $50 \mathrm{nl}$ volumes over $75 \mathrm{~s}$, followed by a 2 min delay before withdrawal of the pipette (Cummings et al., 2005). Previous studies in our laboratory have demonstrated that this volume does not exacerbate damage to the spinal cord. In an acute cell transplant model, mice received hCNS-SCns immediately after SCI. In a delayed cell transplant model, animals were reanesthetized at $30 \mathrm{dpi}$, sutures were removed, and the laminectomy/injured site at T9 was re-exposed. In both paradigms, animals received four injections of hCNS-SCns or vehicle into the intact parenchyma adjacent to the contusion site (Cummings et al., 2005). The survival time for all cell-transplanted and vehicle-injected animals was 12-16 weeks post-SCI. 
Table 2. Antibodies used for histology

\begin{tabular}{lllll}
\hline Antibody & Host & Dilution & Manufacturer & Specificity \\
\hline SC121 & Mouse & $1: 3000-4000$ & StemCells & Human cytoplasm \\
SC123 & Mouse & $1: 3000-4000$ & StemCells & Human GFAP astrocytes \\
GFAP & Rabbit & $1: 60,000$ & DAKO & Pan GFAP astrocytes \\
Fibronectin & Rabbit & $1: 500$ & Sigma-Aldrich & Fibronectin lesion \\
\hline
\end{tabular}

After cell or vehicle injections, a small piece of gel-foam was placed over the site of laminectomy and the musculature was closed with sutures. Animals received lactated Ringer's solution ( $50 \mathrm{ml} / \mathrm{kg}$, s.c.) immediately after surgery and for $3-5 \mathrm{~d}$ postsurgery, as well as buprenorphine $(0.5 \mathrm{mg} / \mathrm{kg}$, s.c.) immediately after injury and for $2 \mathrm{~d}$ thereafter. Due to the immunodeficient nature of NOD-scid mice, and to avoid the possibility of bladder infections, antibiotics were administered daily throughout the 12-16 week duration of the study, rotating the use of Baytril, ciproflaxacin, and ampicillin ( $2.5 \mathrm{mg} / \mathrm{kg}$, s.c., dose for all drugs) every 2 weeks.

Tissue collection and processing. Mice were anesthetized at 12-16 weeks postinjury and transcardially perfused with PBS followed by $4 \%$ PBSbuffered paraformaldehyde. Spinal cord regions corresponding to dorsal roots at T2-T5, T6-T12, and T13-L2 were dissected and postfixed overnight in $4 \%$ PBS-buffered paraformaldehyde, flash frozen at $-65^{\circ} \mathrm{C}$ in isopentane, and stored at $-80^{\circ} \mathrm{C}$. The T6-T12 spinal cords were embedded in Tissue-Tek optimal cutting temperature (OCT) compound and sectioned parasagittally at $30 \mu \mathrm{m}$ on a sliding microtome (Microm). Parasagittal sections were collected and stored in 96-well tissue culture plates filled with $100 \mathrm{~mm}$ Tris with $0.02 \%$ sodium azide and kept at $4{ }^{\circ} \mathrm{C}$ until processed for immunostaining. For diaminobenzidine (DAB) immunohistochemistry, tissue sections were incubated with $10 \% \mathrm{MeOH} / 3 \%$ $\mathrm{H} 2 \mathrm{O} 2$ in $100 \mathrm{~mm}$ Tris to inactivate endogenous peroxide activity and immunostained as described in the study by Hooshmand et al. (2009). Methyl green counterstain was used to visualize nuclei (Sigma-Aldrich). Fluorescence-conjugated immunohistochemistry was performed as described in the study Hooshmand et al. (2009). All antibodies and dilutions are listed in Table 2.

Stereological analysis. Animals containing less than three sections with a visible injury epicenter (minimum number required for obtaining reliable results) were excluded from stereological analyses. Stereology of a randomly selected subgroup of animals $(N=6$ /group $)$ was conducted using an Olympus BX51 Microscope with a motorized stage and StereoInvestigator software (version 7.00.3; MBF Biosciences). The Optical Fractionator probe (Joelving et al., 2006) was used to count the number of SC121 human cells and SC123 human astrocytes. The counting areas were determined by drawing contours at every $1 \mathrm{~mm}$ region (for SC121 ${ }^{+}$ cells) and around the entire spinal cord (for SC123 ${ }^{+}$cells) using a $4 \times$ objective. SC121 or SC123 cells associated with a visible methyl green nuclear stain were counted using a $100 \times$ objective in the corresponding areas. Grid size measurements were determined based on preliminary experimentation to establish low coefficient of error and sufficient total estimated counts per frame ( $3-5$ cells/counting frame). A minimum of three sections where the injury epicenter was clearly visible was analyzed for each animal. Quantification in StereoInvestigator yielded the total number of SC121 or SC123/methyl-green double-labeled cells within each region or the entire spinal cord, respectively. Total SC121 count was calculated as the sum of cells in all $1 \mathrm{~mm}$ regions. Migration was reported as the total number of cells at each region.

Stereological data for SC123 ${ }^{+}$and $\mathrm{SC}_{12} 1^{+}$donor cells was also used to determine the proportion of $\mathrm{SC}_{12} 3^{+}$cells near the lesion (within $1 \mathrm{~mm}$ of the epicenter) versus away from the lesion $(>1 \mathrm{~mm}$ distal to epicenter), based on the identification of the lesion using fibronectin immunoreactivity. For this analysis, the lesion epicenter was identified as the center line of fibronectin immunoreactivity in alternate parasagittal sections, and the total number of cells within $2 \mathrm{~mm}$ of this center line were determined to have proximal localization using StereoInvestigator reconstruction of optical fractionator data.

Volume analyses were performed using the Cavalieri estimator probe in StereoInvestigator. Lesion volume analysis was performed using fi- bronectin immunostaining. The fibronectin ${ }^{+}$region was identified as the lesion epicenter, and a point-grid of known spacing (100 $\mu \mathrm{m}$ apart) was randomly overlayed on the section image. Points were counted using a $20 \times$ objective within the region of interest. This analysis yielded the estimated lesion volume.

\section{PMN depletion studies}

Contusion SCI and cell transplantation. The effect of PMN depletion was only tested in an acute cell transplant paradigm post-SCI. As described above, female NOD-scid mice ( $N=12$ /group, 10 weeks old; The Jackson Laboratory) received a laminectomy at the T9 and 50 kilodyn contusion injuries using the IH Impactor (Precision Systems and Instrumentation) at T9. Before SCI, animals were randomly assigned to receive either anti-Ly6G or IgG2a intraperitoneal injections, described below, followed by hCNS-SCns transplants or vehicle injections (Table 1). On the day of transplantation, Passage 9 multipotent hCNS-SCns grown as neurospheres were dissociated into a single-cell suspension, and cells $(75,000 / \mu \mathrm{l})$ or vehicle were injected into the intact parenchyma at T9. Immediately after SCI, each mouse received a total of four injections of hCNS-SCns or vehicle in the intact parenchyma adjacent to the contusion site (Cummings et al., 2005). The survival time for all animals was $90 \mathrm{dpi}(\sim 12$ weeks post-SCI).

Anti-Ly6G intraperitoneal injections and flow cytometric analysis. PMN depletion was accomplished using anti-Ly6G (i.p. injections, $100 \mu \mathrm{l}$ volume; Clone 1A8, Bio X Cell) according to a modified injection scheme from a previous study (Saiwai et al., 2013). One day before SCI and cell transplantation, mice $(N=12 /$ group $)$ received $200 \mu \mathrm{g}$ of either antiLy6G or IgG2a isotype (Bio X Cell) control. Mice also received additional injections $(100 \mu \mathrm{g})$ of anti-Ly6G or IgG2a immediately following SCI/ transplantation and every $3 \mathrm{~d}$ after for up to $15 \mathrm{dpi}$. Anti-Ly6G injections did not result in any fatality or adverse effect/toxicity. Furthermore, an additional subset of animals ( $N=8$ per group) that received SCI only (without cell transplant) was used to confirm short-term PMN depletion by anti-Ly6G in the blood and spinal cord. These animals were sacrificed at $1 \mathrm{dpi}(N=4)$ or $14 \mathrm{dpi}(N=4)$, while the rest of the animals that received cell transplant and either anti-Ly6G or IgG2 were sacrificed at 90 dpi (Table 1).

PMN depletion in the blood and spinal cord was assessed using flow cytometry. Briefly, blood samples $(20 \mu \mathrm{l})$ from the tail vein were collected in $1.5 \mathrm{ml}$ Eppendorf Tubes containing $1 \mathrm{ml}$ of cold PBS with $2 \mathrm{~mm}$ EDTA. Spinal cord tissues from T8-T10 from randomly selected anti-Ly6G-and IgG2a-treated animals were removed, and dissociated mechanically and enzymatically according to previous study (Beck et al., 2010). Spinal cord cell solution was further purified from myelin debris using Myelin Removal Magnetic Beads II Kit on an autoMACS Pro Separator (Miltenyi Biotec) according to the manufacturer instructions.

Collected cells isolated from blood or spinal cord tissues were suspended in $0.85 \% \mathrm{NH} 4 \mathrm{Cl} 2$ lysis solution and washed with $1 \mathrm{ml}$ of PBS with 2 mM EDTA. A master mix of antibodies (all were obtained from BioLegend and diluted at 1:100 in PBS) was prepared containing PE/Cy7 anti-mouse CD45 (catalog \#103114; RRID:AB_312979), APC antimouse CD11b (catalog \#101211; RRID:AB_312794), PE anti-mouse Ly6G (catalog \#127607; RRID:AB_1186104), and FITC anti-mouse Ly6C (catalog \#128005; RRID:AB_1186134). A volume of $100 \mathrm{ml}$ of antibody master mix was distributed to each cell sample, incubated for $20 \mathrm{~min}$, washed with $1 \mathrm{ml}$ of PBS, and analyzed on an LSII (BD Biosciences) flow cytometer. Cell viability detected by propidium iodide (Sigma-Aldrich) was typically $>90 \%$. Ly6G and Ly6C have been used previously to reliably identify PMNs and monocytes in the blood and spinal cord tissue (Saiwai et al., 2013; Daley et al., 2008). For all samples, the CD45 ${ }^{+}$/ $\mathrm{CD} 11 \mathrm{~b}^{+}$leukocyte cell population was gated to assess for $\mathrm{Ly}_{6 \mathrm{G}}{ }^{+} / \mathrm{Ly} \mathrm{CC}^{-}$ PMNs and Ly6G ${ }^{-} / \mathrm{Ly}_{6} \mathrm{C}^{+}$monocytes. The mean values of PMNs and monocytes as determined by flow cytometry were expressed as percentage $( \pm \mathrm{SE})$ relative to $\mathrm{CD} 45^{+} / \mathrm{CD} 11 \mathrm{~b}{ }^{+}$leukocytes.

RNA sequencing and analysis. This analysis compared animals that received no SCI + no administration of IgG2a or anti-Ly6G (naive, $N=$ $4)$, animals that received $\mathrm{SCI}+\operatorname{IgG} 2 \mathrm{a}(N=4)$, and animals that received $\mathrm{SCI}+$ anti-Ly6G $(N=4)$. Mice were sacrificed $1 \mathrm{dpi}$, and total RNA was collected from whole $\mathrm{T} 8-\mathrm{T} 10$ vertebral spinal cord. 
RNA was extracted using TRIzol (Life Technologies), and DNasetreated and purified using a NucleoSpin RNA II kit (Macherey-Nagel). Purified RNA was quantified using a Qubit 2.0 Fluorometer (Life Technologies) and checked for quality using an Agilent Technologies Bioanalyzer 2100. Library construction and sequencing were performed at the University of California, Irvine, Genomics High-Throughput Facility. cDNA libraries were made with a TruSeq RNA Library Prep Kit version 2 (Illumina) according to manufacturer instruction and sequenced on an Illumina HiSeq 4000 platform producing 30 million paired-end reads with a read length of 100 . Before read mapping, each sample was subjected to qualitative control analysis by FastQC tool (http://www. bioinformatics.babraham.ac.uk/projects/fastqc/). Subsequently, potential ribosomal contamination was removed by the SortMeRNA tool (Kopylova et al., 2012) and low-quality bases $(\mathrm{Q}<30)$ were filtered out by the Trimmomatic tool (Bolger et al., 2014). Then, RNA sequencing (RNAseq) reads were mapped to mouse reference genome GRCm38 version 87 using STAR aligner, and the uniquely mapped reads were summarized at the gene level using featureCounts (Liao et al., 2014). Differential gene expression analysis was performed on TMM normalized counts implemented in EdgeR (McCarthy et al., 2012). A false discovery rate-corrected $p$ value of $<0.05$ was used in determining significant differentially expressed genes for respective comparisons. Principal component analysis (PCA) was performed using R package "stats" and plotted using JMP statistical tool (version 11, SAS Institute). Hierarchical clustering was performed and visualized using the $\mathrm{R}$ package ggplot2_2.2.1. Tissue-specific expression was determined in FunRich (Pathan et al., 2015). The functionally relevant biological information for differentially expressed genes (DEGs) were identified using geneSCF tool (Subhash and Kanduri 2016; extended data Fig. 7-1 available at https:// 10.1523/JNEUROSCI.2785-16.2017.f7-1). The top enriched gene ontology (GO) terms were depicted in Figure 7F using R package ggplot2_2.2.1.

Tissue collection, processing, and analysis. Mice were anesthetized at 12 weeks postinjury and transcardially perfused with PBS followed by $4 \%$ PBS-buffered paraformaldehyde. Spinal cord regions corresponding to dorsal roots at T2-T5, T6-T12, and T13-L2 were dissected and postfixed overnight in $4 \%$ PBS-buffered paraformaldehyde, flash frozen at $-65^{\circ} \mathrm{C}$ in isopentane, and stored at $-80^{\circ} \mathrm{C}$. The T6-T12 spinal cords were embedded in Tissue-Tek OCT compound and sectioned coronally at $30 \mu \mathrm{m}$ using a CryoJane tape transfer system (Leica Biosystems). A subset of animals (IgG2a, $N=2$; anti-Ly6G, $N=2$ ) was randomly selected for sectioning in the parasagittal plane on a sliding microtome (Microm) using the same method described above. CryoJane sections were stored at $-20^{\circ} \mathrm{C}$ until processing for immunohistochemical or other staining. For immunohistochemistry, frozen CryoJane sections were brought to room temperature. Sections were processed for antigen retrieval using Buffer A, pH 6, in the Retriever 2100 System (PickCell Laboratories).

All primary antibodies and dilutions that were used for immunolabeling are listed in Table 2, including human cytoplasm SC121, human GFAP SC123, and fibronectin. The secondary antibodies used were either biotin-conjugated or fluorescence-conjugated affinipure $\mathrm{F}\left(\mathrm{ab}^{\prime}\right) 2$ fragment secondary antibodies (Jackson ImmunoResearch). DAB, methyl green counterstaining, and fluorescence-conjugated immunohistochemistry were performed as described above and in a previous study (Hooshmand et al., 2009). Fluorescent images were captured on the Zeiss LSM510 Ultraview VOX Spinning Disk Confocal Microscope; saved as red, green, and blue; and final images were merged using Volocity 5.0 software.

Stereological analysis. As above, stereology of a randomly selected subgroup of animals ( $N=5$ /group) was conducted using an Olympus BX51 Microscope with motorized stage and StereoInvestigator to estimate unbiased total SC121 human cell and SC123 human astrocyte numbers, and volumes of fibronectin lesion SC121 and SC123 clustering. Uniform random sampling of the tissue was performed according to standard stereological principles. Sampling parameters (i.e., grid size and counting frame size) were empirically determined to arrive at low coefficients of error. Briefly, total numbers of SC $121^{+}$human cells were determined by unbiased stereology in 1 of 12 intervals from coronal spinal cord sections $0.36 \mathrm{~mm}$ apart using systematic random sampling with an optical fractionator probe and StereoInvestigator version 9 (MicroBrightField). Optical fractionator grid size $(\mathrm{SC} 121,350 \times 350 \mu \mathrm{m}$; SC123, $200 \times 200 \mu \mathrm{m})$ and counting frame size (SC121, $35 \times 35 \mu \mathrm{m}$; SC123, $50 \times 50 \mu \mathrm{m})$ were empirically determined to yield average Gundersen cumulative error values of $<0.1$.

As described above, stereological data for $\mathrm{SC} 23^{+}$cells was used to determine the number of $\mathrm{SC} 23^{+}$cells near the lesion (within $1 \mathrm{~mm}$ of the epicenter) versus away from the lesion ( $>1 \mathrm{~mm}$ distal to epicenter), based on the identification of the lesion using Fibronectin immunoreactivity. For this analysis, the lesion was identified as the volume occupied by fibronectin immunoreactivity in alternate parasagittal sections. The total number of cells within $2 \mathrm{~mm}$ of this lesion was determined to have proximal localization using StereoInvestigator reconstruction of optical fractionator data. Furthermore, the distribution/migration of SC121 human cells and SC123 human astrocytes was represented as the number of cells that were binned at distance (in millimeters) away from the spared tissue region.

A Cavalieri probe (grid size, $20 \times 20 \mu \mathrm{m}$; SI9, MicroBrightField) was used to analyze total volumes of spinal cord, fibronectin lesion, SC121 clustering, and S123 clustering in 1 of 12 intervals from coronal spinal cord sections $0.36 \mathrm{~mm}$ apart, at $10 \times$ magnification for spinal cord and $20 \times$ magnification for fibronectin lesion and clustering volumes.

\section{Behavioral tasks and assessments}

Locomotor recovery in mice $(N=10-16 /$ group; Table 1$)$ was assessed using CatWalk gait analysis to assess kinematic parameters (Koopmans et al., 2005). CatWalk testing was conducted by blinded technicians $1 \mathrm{~d}$ before SCI and every 4 weeks until sacrifice.

\section{Statistics}

Statistics were performed using Prism (version 5, GraphPad). Comparisons between acute versus delayed cell transplants, cell transplant versus vehicle, and IgG2a versus anti-Ly6G treatments for flow cytometric analysis, stereological quantification, and behavioral assay data (CatWalk) were analyzed using individual two-tailed Student's $t$ tests. Human cell distribution/migration of SC121 human cells and SC123 human astrocytes was analyzed using two-way ANOVA followed by Bonferroni post hoc $t$ tests. Time courses of blood PMNs and spinal cord-infiltrated PMNs were analyzed using one-way ANOVA followed by Bonferroni post hoc $t$ tests. Significance was defined as $p<0.05$.

\section{Study approval}

All animal housing conditions, surgical procedures, and postoperative care was conducted according to the Institutional Animal Care and Use Committee guidelines at the University of California, Irvine.

\section{Results}

\section{Acute transplantation of hCNS-SCns altered donor cell astroglial differentiation and distribution and did not improve recovery after SCI}

Because these studies involved xenogeneic transplantation, we used a constitutively immunodeficient mouse model of SCI that we have previously shown to enable sufficient human donor cell engraftment success to accurately assess long-term cell integration and effects on locomotor recovery of function (Anderson et al., 2011). While the adaptive immune response is absent in these animals, this NOD-scid mouse model has an intact cellular innate immune response including PMN and macrophage/microglial recruitment, and histopathological characteristics comparable to other laboratory mouse strains following SCI (Luchetti et al., 2009). Accordingly, vertebral level T9 contusion-injured NODscid mice received bilateral hCNS-SCns transplants or vehicle into the spared parenchyma $1 \mathrm{~mm}$ above and below the SCI epicenter either immediately post-SCI (acute, $0 \mathrm{dpi}$ ) or $30 \mathrm{~d}$ postSCI (delayed, $30 \mathrm{dpi}$ ). All animals received 75,000 hCNS-SCns in a total injection volume of $1 \mu \mathrm{l}$ distributed across four injection sites, as described under Materials and Methods.

Histological analyses using a human-specific cytoplasmic antibody (Fig. 1 A, B, SC121/STEM121, brown label) demonstrated 

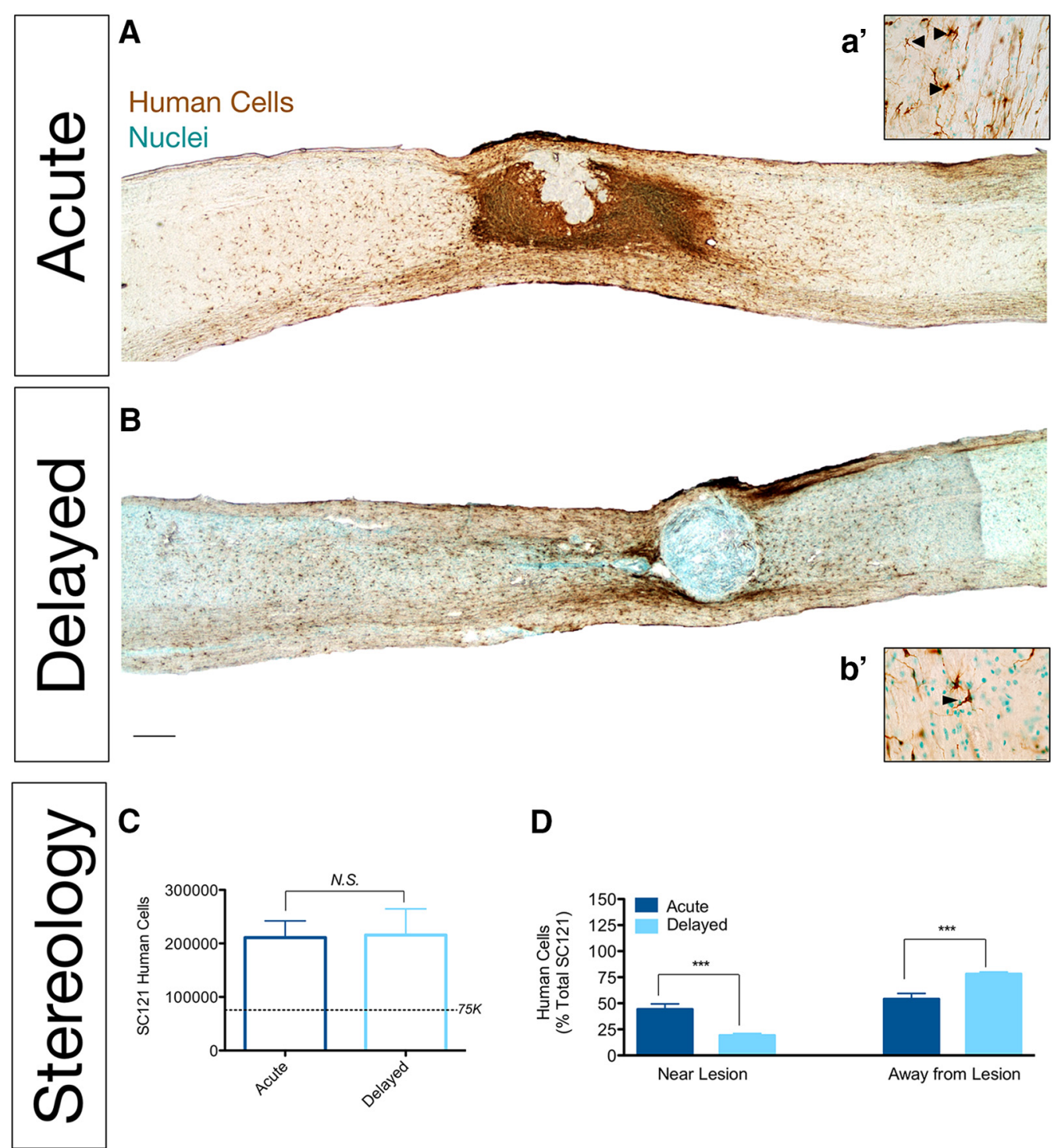

D

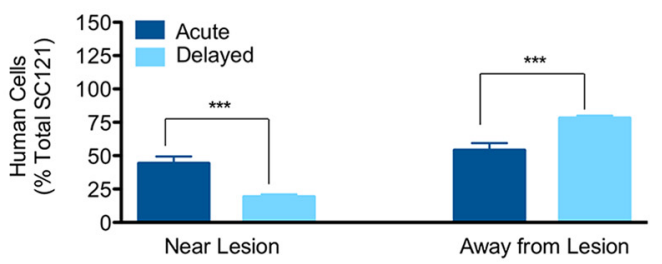

Figure 1. hCNS-SCns transplanted at acute and delayed time points post-SCl engrafted similarly but differed in their distribution post-SCI. $\boldsymbol{A}, \boldsymbol{a}^{\prime}, \boldsymbol{B}, \boldsymbol{b}^{\prime}$, Immunostaining using a human-specific marker (SC121, brown) demonstrated hCNS-SCns survival in acute $\left(\boldsymbol{A}, \boldsymbol{a}^{\prime}\right)$ and delayed $\left(\boldsymbol{B}, \boldsymbol{b}^{\prime}\right)$ transplants. $\boldsymbol{A}, \boldsymbol{B}$, While most human cells were localized away from the lesion by 12 weeks after delayed transplantation $(\boldsymbol{B})$, following acute transplantation $(\boldsymbol{A})$, many human cells formed dense clusters near the lesion. $\boldsymbol{C}$, Stereological quantification of human cells revealed equivalent numbers of engrafted hCNS-SCns ( $N=6$ /group; Student's $t$ test, $p=0.94)$. The dashed line indicates the number of cells originally transplanted (75,000/animal). $\boldsymbol{D}$, Significantly more hCNS-SCns were localized proximal ( $1 \mathrm{~mm}$ rostral and caudal) to the lesion in animals receiving acute compared with delayed transplantation. In contrast, significantly more hCNS-SCns were localized distal ( $>1 \mathrm{~mm}$ rostral and caudal) to the lesion in animals receiving delayed versus acute transplantation. For this analysis, the lesion epicenter was identified as the center line of fibronectin immunoreactivity in alternate sections. The total number of cells within $2 \mathrm{~mm}$ of this center line was determined to have proximal localization using Stereolnvestigator reconstruction of optical fractionator data. ${ }^{* * *} p<0.001$, Student's $t$ test. Scale bars: $\boldsymbol{A}, \boldsymbol{B}, 250 \mu \mathrm{m} ; \boldsymbol{a}^{\prime}$ and $\boldsymbol{b}^{\prime}, 25 \mu \mathrm{m}$. Values are shown as the mean \pm SEM.

donor human cell engraftment in $100 \%$ of animals $(N=16)$ that received hCNS-SCns in either acute or delayed transplantation post-SCI. Blinded, unbiased stereological quantification at 12-16 weeks post-transplantation using the optical fractionator probe revealed 210,000 $\pm 31,023 \mathrm{hCNS}$-SCns for mice receiving acute transplantation and $215,700 \pm$ 48,980 for mice receiving delayed transplantation (Fig. 1C), demonstrating no differences in donor human cell engraftment. Surprisingly, however, mice receiving acute transplantation exhibited dense clustering of hCNS-SCns proximal to the lesion that was not apparent after delayed transplantation (Fig. $1 A, B$ ). This observation was verified by stereological quantification, which demonstrated a significantly higher number of hCNS-SCns localized in the spared parenchyma near the lesion (within $1 \mathrm{~mm}$ of the epicenter, as described in Materials and Methods) in acute versus delayed transplantation animals
(Fig. $1 D ; 93,260 \pm 15,760$ in acute vs 38,380 \pm 7780 in delayed). The reverse was apparent for hCNS-SCns that migrated away from the lesion $(>1 \mathrm{~mm}$ distal to the epicenter), with significantly higher cell numbers distal to the epicenter in delayed versus acute transplants (Fig. 1D). Together, these data show no difference in total hCNS-SCns engraftment between transplant paradigms; however, there was a striking difference in the distribution/localization of hCNS-SCns within the injured spinal cord.

hCNS-SCns do not alter lesion volume after delayed transplantation (Hooshmand et al., 2009; Salazar et al., 2010). Here, we assessed the localization of hCNS-SCns at the lesion epicenter and tested the effect of donor human cells on lesion volume after acute transplantation using fluorescent immunolabeling for SC121 and fibronectin. Although large numbers of hCNS-SCns were densely packed adjacent to the fibronectin ${ }^{+}$epicenter 12 weeks 


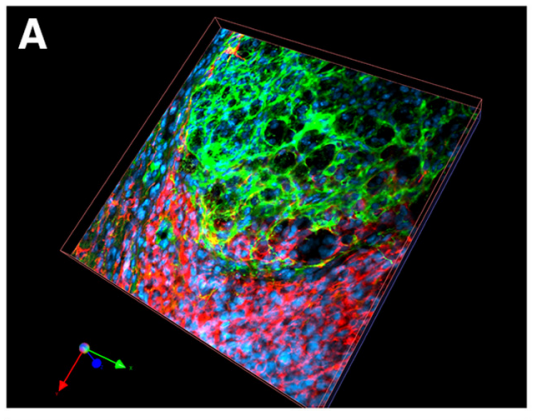

Human Cells Fibronectin Hoechst

\section{C}
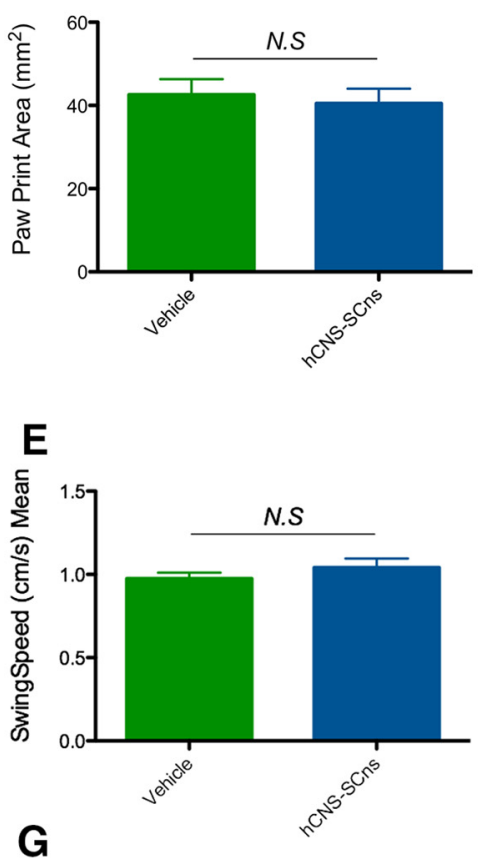

\section{Human Astrocytes} Nuclei

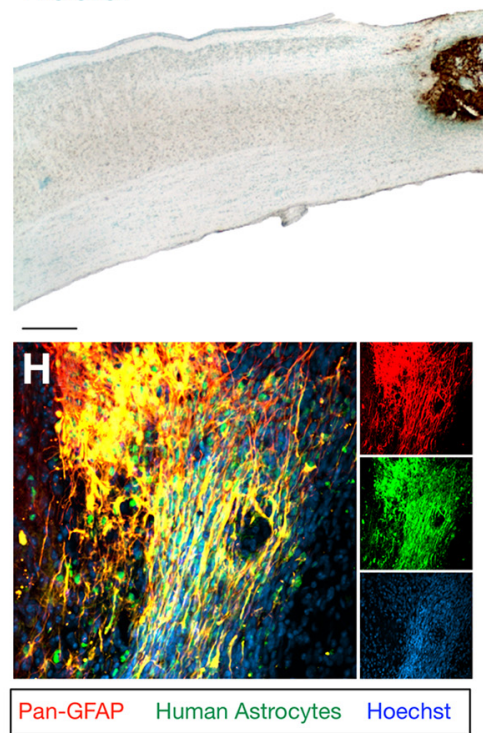

\section{B}

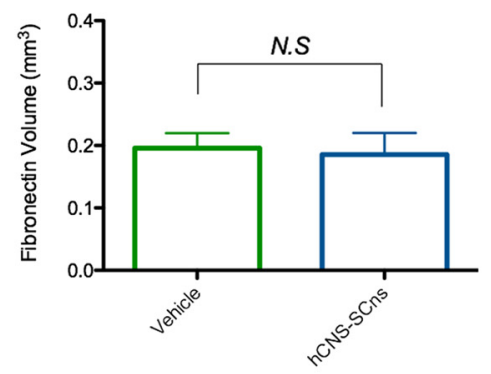

D

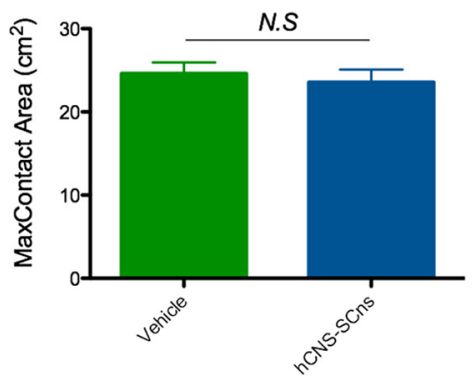

$\mathbf{F}$

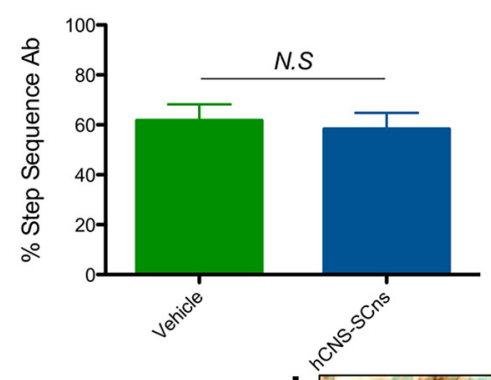

g'

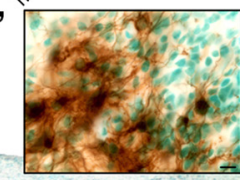

Figure 2. Acute transplantation of hCNS-SCns resulted in human astroglial differentiation and localization near the lesion epicenter but did not affect lesion volume or functional recovery after $\mathrm{SCl}$. $A$, Minimal overlap of $\mathrm{SC}_{21} 1^{+}$human cells (red) and fibronectin ${ }^{+}$lesion (green) revealed few hCNS-SCns entering the lesion epicenter. $\boldsymbol{B}$, Stereological quantification for the volume

after acute transplantation, few were localized within the fibronectin ${ }^{+}$epicenter itself (Fig. 2A, hCNS-SCns, red; fibronectin, green; colocalization, yellow), suggesting that acutely transplanted cells migrated toward the epicenter but avoided the epicenter core. Blinded, unbiased stereological quantification using the Cavalieri probe revealed no significant differences between fibronectin $^{+}$regions in mice receiving acute hCNSSCns transplants versus vehicle controls (Fig. 2B), demonstrating that acutely transplanted hCNS-SCns neither increased nor decreased lesion volume.

hCNS-SCns transplantation at delayed time points promotes locomotor recovery (Cummings et al., 2005; Salazar et al., 2010). In the present study, despite comparable engraftment (Fig. 1), acute transplantation was not associated with functional recovery as determined by open-field locomotor assessment or ladderbeam analysis (data not shown). Furthermore, CatWalk kinematic gait analysis (Hamers et al., 2006), a more sensitive assessment of the fine aspects of locomotion, did not reveal significant differences between acute hCNSSCns transplant versus vehicle groups in any parameters including hindpaw print area, hindpaw maximum contact area, mean swing speed, and the percentage of step sequence $\mathrm{Ab}$ (Fig. 2C-F). Collectively, our data suggest that, despite evidence of efficacy after delayed transplantation, acute hCNS-SCns transplantation at 0 dpi failed to promote locomotor recovery.

hCNS-SCns transplantation at delayed time points, 9 and $30 \mathrm{dpi}$, respectively, results in predominant differentiation into oligodendrocytes (68\% and 50\%), some neurons $(25 \%$ and $40 \%)$, and very few astrocytes (3\% and 8\%; Cummings et al., 2005; Salazar et al., 2010). In contrast, in

\section{$\leftarrow$}

of fibronectin ${ }^{+}$lesions demonstrated no significant differences between vehicle and hCNS-SCns groups ( $N=6$ /group; Student'st test, N.S. $=p>0.05$ ), suggesting that hCNS-SCns transplantation did not alter the size of the lesion. $\mathbf{C}-\boldsymbol{F}$, hCNSSCns engraftment was not associated with improvements or decrements in recovery of function assessed by CatWalk gait analysis, including hindpaw print area ( $(C)$, hindpaw maximum contact area $(\boldsymbol{D})$, swing speed mean $(\boldsymbol{E})$, and the percentage of step sequence $A b s(\boldsymbol{F}) . N=16 /$ group, Student's ttests, N.S. = $p>0.05$. G, A majority of human-specific astrocytes $\left(\mathrm{SC}_{\mathrm{C}} \mathrm{S3}^{+}\right.$ cells, brown) formed dense clusters near the lesion. $\boldsymbol{g}^{\prime}$, Highpower image of $\mathrm{SC}_{123}{ }^{+}$labeling from $\boldsymbol{G}$. $\boldsymbol{H}$, Near the injury epicenter, hCNS-SCns exhibited predominant colocalization with both pan-GFAP (red) and SC123 (green). I, Stereological quantification of $\mathrm{SC}_{123}{ }^{+}$cells revealed that $86.3 \%$ of donor human cells exhibiting astrocytic differentiation were localized near the lesion. $N=6 /$ group, Student's $t$ test, ${ }^{* * *} p<$ 0.001. Scale bars: $\boldsymbol{g}^{\prime}, 25 \mu \mathrm{m} ; \boldsymbol{G}, 250 \mu \mathrm{m}$. Values are given as the mean \pm SEM. 

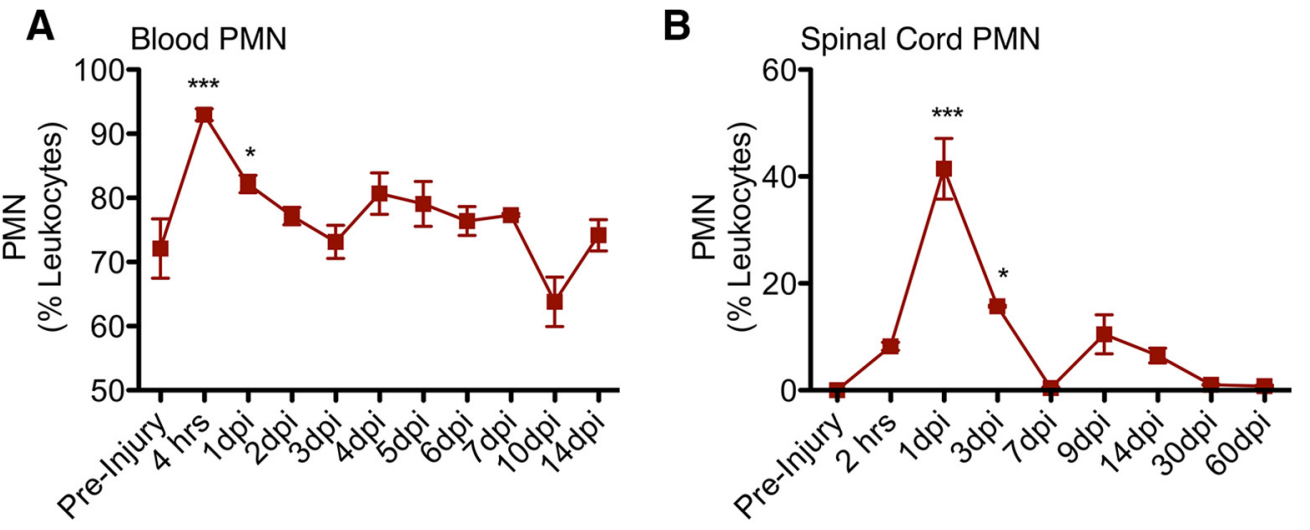

Figure 3. After SCl, the number of PMNs increased acutely in the blood and spinal cord of mice. $A$, NOD-scid mice were given a moderate ( 50 kilodyn) contusion injury at T9, and blood samples were collected before injury and daily from $4 \mathrm{~h}$ to $14 \mathrm{dpi}$. $\boldsymbol{B}$, For spinal cord PMN infiltration, another set of animals was given a moderate (50 kilodyn) contusion injury at T9 and were sacrificed at $2 \mathrm{~h}, 1 \mathrm{dpi}, 3 \mathrm{dpi}, 7 \mathrm{dpi}, 9 \mathrm{dpi}, 14 \mathrm{dpi}, 30 \mathrm{dpi}$, or $60 \mathrm{dpi}$. Blood ( $N=4-8 /$ group) and spinal cord ( $N=4 /$ group) cells were immunolabeled for CD45, CD11b, Ly6G, and Ly6C. For all samples, the $\mathrm{CD}_{45}{ }^{+} / \mathrm{CD} 11 \mathrm{~b}{ }^{+}$leukocyte cell population was gated to assess for Ly6G ${ }^{+} / \mathrm{Ly}_{6 \mathrm{C}}{ }^{-}$PMNs. The percentage of PMNs is expressed as the number of PMNs relative to $\mathrm{CD} 45^{+} / \mathrm{CD} 11 \mathrm{~b}{ }^{+}$leukocytes. ${ }^{*} p<$ $0.05 ;{ }^{* * *} p<0.001$, one-way ANOVA followed by Bonferroni post hoc $t$ tests, $N=4-8 /$ group. Values are given as the mean \pm SEM.

the present acute transplant study, bright-field and confocal imaging using a human-specific astrocytic marker (SC123/ STEM123) revealed the presence of many $\mathrm{SC}_{123}{ }^{+}$human astrocytes proximal to the injury epicenter (Fig. 2G,H), corresponding to regions of dense donor human cell clusters. The specificity of SC123 for GFAP was validated, as $\mathrm{SC}_{123}{ }^{+}$cells adjacent to the lesion exhibited nearly complete overlap with pan-GFAP ${ }^{+}$cells (data not shown), suggesting that the majority of cells in this region were $\mathrm{GFAP}^{+}$astrocytes and human in origin. Blinded, unbiased stereological quantification using the optical fractionator probe demonstrated that $86.3 \%$ of $\mathrm{SC}_{123}{ }^{+}$ human astrocytes in the spinal cords of mice receiving acute hCNS-SCns transplantation were localized in the spared parenchyma near the lesion (within $1 \mathrm{~mm}$ of the epicenter; Fig. 2I), suggesting that human donor cells were recruited toward the epicenter, where they differentiated into astrocytes. While studies have suggested that the injured spinal cord niche is gliogenic (Shihabuddin et al., 2000; Cao et al., 2001), there has been a paucity of empirical studies to determine whether variations in host niche and/or cellintrinsic properties drive fate decisions of transplanted cells (Monje et al., 2003). Because PMNs are specifically and selectively recruited to the epicenter of the acute post-SCI microenvironment in humans (Fleming et al., 2006), rats (Beck et al., 2010), and mice (Saiwai et al., 2013), we next investigated the role of PMNs in modulating donor human cell astroglial fate, migration, and associated functional recovery in the acute SCI niche.

\section{Anti-Ly6G administration specifically depleted PMNs after SCI}

As the first immune cells to populate the site of injury, PMNs have been suggested to affect injury and subsequent processes through physical PMN-to-cell contact (Dinkel et al., 2004) and the production of free radicals (Yagisawa et al., 1996), proteases (de Castro et al., 2000), and proinflammatory cytokines (Lenzlinger et al., 2001). As described above, NOD-scid mice have a comparable innate cellular immune response to other mouse strains. Here, we verified the presence of PMNs $\left(\mathrm{Ly}_{6 \mathrm{G}}{ }^{+} / \mathrm{Ly} 6 \mathrm{C}^{-}\right)$ using flow cytometry, demonstrating that NOD-scid mice have a robust and transient PMN infiltration that peaked at $1 \mathrm{dpi}$ (Fig. $3 B$ ) and was localized to the spinal cord lesion epicenter (data not shown). The timing and localization of this response were consistent with those determined in other studies in rats and mice without adaptive immune system ( $\mathrm{T}$ - and $\mathrm{B}$-cell) deficiencies (Luchetti et al., 2009; Stirling et al., 2009; Beck et al., 2010). Further, a robust presence of PMNs was detected in the blood of NOD-scid mice after SCI, showing a peak (90\% of leukocytes) of PMNs at $4 \mathrm{~h}$ post-SCI and gradually returning to preinjury levels (60\% of leukocytes) after 10 dpi (Fig. $3 A$ ).

Having validated the retention of an innate cellular immune response after SCI in NOD-scid mice, we next tested the specificity and efficiency of anti-Ly6G to deplete PMNs in the blood and spinal cords of SCI mice. All mice received a mid-thoracic moderate contusion SCI as described in Materials and Methods, and either IgG2a or anti-Ly6G administration via intraperitoneal injection $1 \mathrm{~d}$ before SCI, as well as immediately after SCI, and every $3 \mathrm{~d}$ until animals were sacrificed at 1 or $14 \mathrm{dpi}$ (Fig. $4 A$ ). Flow cytometric analysis demonstrated that, compared with IgG2atreated animals, anti-Ly6G-treated animals exhibited efficient depletion of PMNs in the blood at 1 dpi (Fig. $4 B-D ; 1.23 \pm 0.65 \%$ of leukocytes; $N=8$ ), which was sustained through 14 dpi (Fig. $4 E ; 8.46 \pm 5.17 \%$ of leukocytes; $N=4$ ). Furthermore, anti-Ly6Gtreated animals exhibited comparable PMN depletion efficiency in the spinal cord at $1 \mathrm{dpi}$ (Fig. $4 F-H ; 4.25 \pm 1.78 \%$ of leukocytes; $N=4$ ) and up to 14 dpi (Fig. $4 I ; 2.46 \pm 0.43 \%$ of leukocytes; $N=$ 4). Interestingly, anti-Ly6G treatment also resulted in an increasing proportion of monocytes $\left(\mathrm{Ly} 6 \mathrm{G}^{-} / \mathrm{Ly}_{6} \mathrm{C}^{+}\right.$) detected in blood at 1 and $14 \mathrm{dpi}$ (Fig. $5 A-D$ ), and in spinal cord tissue at $1 \mathrm{dpi}$ but not 14 dpi (Fig. $5 E-H$ ). We hypothesized that this change in proportion was not the result of an increase in monocytes, but rather the result of a shift due to the depleted PMN population in anti-Ly6G-treated animals. We tested this possibility by analyzing the absolute number of PMNs or monocytes per 5000 events counted via flow cytometry. Anti-Ly6G-treated animals exhibited a dramatic reduction in PMN number counted via this method compared with IgG2a-treated animals, at 1 and $14 \mathrm{dpi}$ in both blood (Fig. 6A, C) and spinal cord (Fig. 6E, G). In contrast, there was no difference in the monocyte number counted between IgG2a and anti-Ly6G-treated groups at 1 and $14 \mathrm{dpi}$ in either blood (Fig. $6 B, D$ ) or spinal cord (Fig. $6 F, H$ ). These data demonstrate that anti-Ly6G efficiently and specifically depleted PMNs and did not affect monocyte absolute cell number after SCI. We next investigated whether the specific PMN depletion via anti-Ly6G injections could alter the fate and migration of trans- 

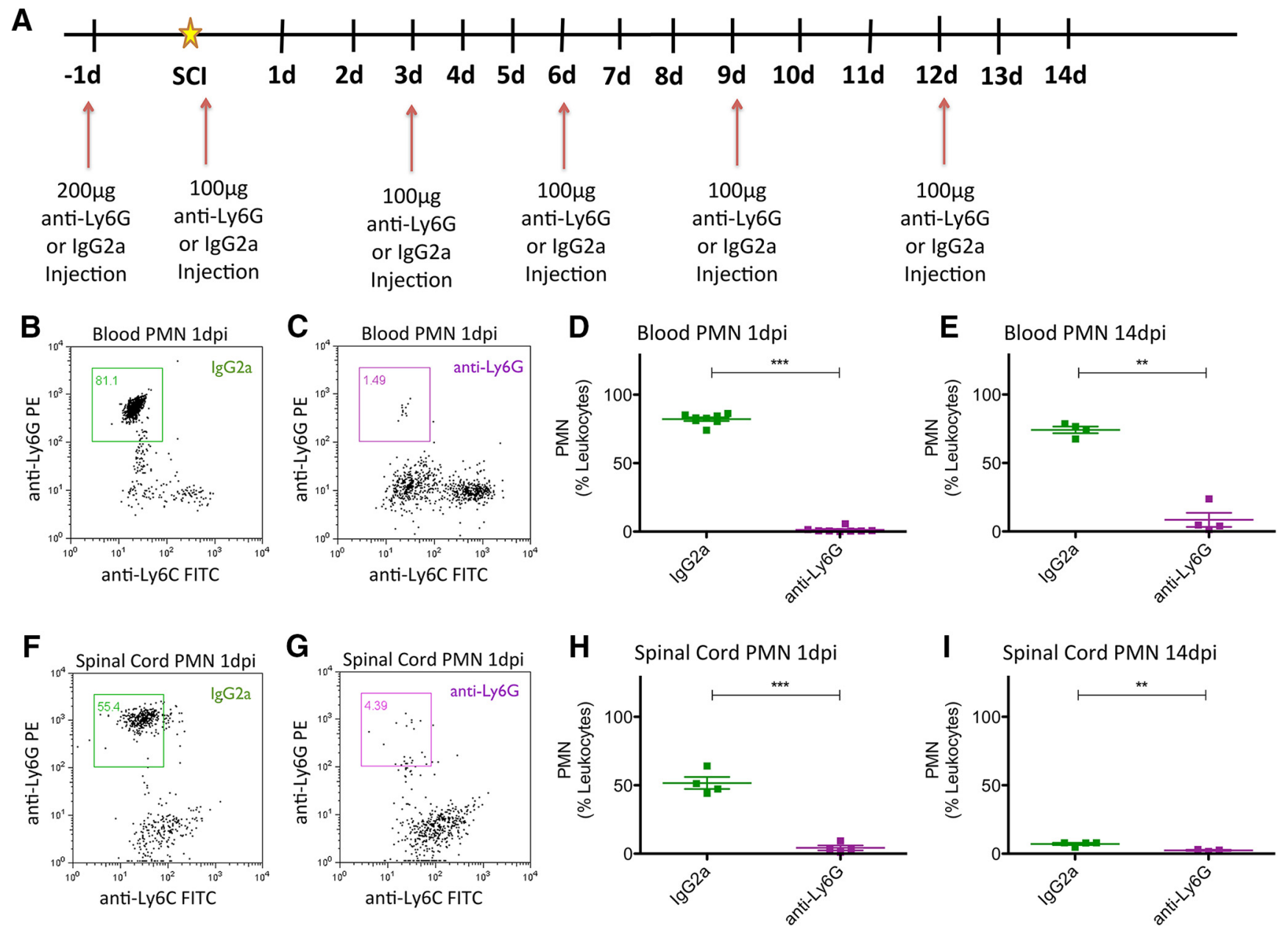

Figure 4. Anti-Ly6G depleted PMNs in blood and spinal cord at $1 \mathrm{dpi}$ and up to $14 \mathrm{dpi}$. All NOD-scid mice received a moderate (50 kilodyn) contusion injury at T9. A, Anti-Ly6G or IgG2a were administered intraperitoneally to mice $1 \mathrm{~d}$ before $\mathbf{S C l}$, immediately after $\mathrm{SCl}$, and every $3 \mathrm{~d}$ thereafter for up to $14 \mathrm{dpi}$, until the animals were sacrificed at 1 or $14 \mathrm{dpi}$. $\boldsymbol{B}$ - $\boldsymbol{E}$, Blood samples collected from these animals at $1 \mathrm{dpi}(\boldsymbol{B}-\boldsymbol{D})$ and $14 \mathrm{dpi}(\boldsymbol{E})$ were assessed for PMN cell counts via flow cytometry. $\boldsymbol{F}-\boldsymbol{I}$, Likewise, spinal cord cells collected from animals at $1 \mathrm{dpi}(\boldsymbol{F}-\boldsymbol{H})$ and $14 \mathrm{dpi}(\boldsymbol{I})$ were assessed for PMN cell counts. Blood cells ( $N=8 /$ group at $1 \mathrm{dpi} ; N=4 /$ group at $14 \mathrm{dpi}$ ) and spinal cord cells ( $N=4 /$ group at 1 and $14 \mathrm{dpi}$ ) were immunolabeled for CD45, CD11b, Ly6G, and Ly6C. For all samples, the $\mathrm{CD} 45^{+} / \mathrm{CD} 11 \mathrm{~b}^{+}$leukocyte cell population was gated to assess $\mathrm{Ly}_{6 \mathrm{G}}{ }^{+} / \mathrm{Ly}_{6 \mathrm{C}}{ }^{-}$PMNs. PMN counts are expressed as a proportion $(\%)$ of CD $45^{+} / \mathrm{CD} 11 \mathrm{~b}^{+}$leukocytes. ${ }^{* * *} p<$ $0.001,{ }^{* *} p<0.01$, Student's $t$ tests. Values are given as the mean \pm SEM.

planted hCNS-SCns and restore the potential for donor human cells to promote the recovery of function.

\section{Anti-Ly6G altered gene expression in the host microenvironment after SCI}

Anti-Ly6G injection produced specific PMN depletion, which we predicted to alter the host injury microenvironment. We tested the effect of PMN depletion on the host injury microenvironment using RNAseq analysis. Total RNA was collected for RNAseq and gene expression analysis from naive control (no SCI, no IgG2a, or anti-Ly6G injection, $N=4)$, SCI + IgG2a-treated $(N=4)$, and SCI + anti-Ly6G-treated $(N=4)$ mice 1 dpi. We selected $1 \mathrm{dpi}$ because this represents both the peak of PMN infiltration and the early period after hNSC transplantation in our paradigm. Changes in overall gene expression were most apparent between naïve and injured spinal cord, regardless of IgG2a or anti-Ly6G treatment (Fig. $7 A, B$ ). Surprisingly, a comparison of SCI + IgG2a and SCI + anti-Ly6G treatment groups revealed only 25 genes with significant expression differences, a majority of which were associated with inflammation (Fig. $7 \mathrm{C}-$ $F)$. Mapping to a multitissue gene expression dataset using a Human Proteome Map (Kim et al., 2014) demonstrated that identified genes were predominantly associated with innate and adaptive immune cell populations (Fig. $7 E$ ); a similar result was observed in gene ontology enrichment analysis (Fig. $7 F$ ). These data suggest that the effect of injury on gene expression patterns in the spinal cord vastly outweighs the changes produced in the SCI microenvironment as a result of PMN depletion. Moreover, PMN depletion via anti-Ly6G treatment resulted in a surprisingly small subset of expression changes in the acute microenvironment, which were principally confined to inflammatory cells, suggesting highly specific changes to the host microenvironment at this time point.

Anti-Ly6G depleted PMN following cell transplantation and did not alter host fibronectin lesion volume after SCI

For these studies, all mice received a mid-thoracic moderate contusion SCI and were randomized into one of the following four groups: vehicle + IgG2a, vehicle + anti-Ly6G, hCNS-SCns + IgG2a, or hCNS-SCns + anti-Ly6G. Because these studies reflect an immediate post-SCI transplantation paradigm, all postinjury and post-transplantation times are referred to in dpi. Animals received IgG2a or anti-Ly6G intraperitoneal injection $1 \mathrm{~d}$ before SCI; immediately after SCI; and at 3, 6, 9, 12, and 15 dpi. Imme- 

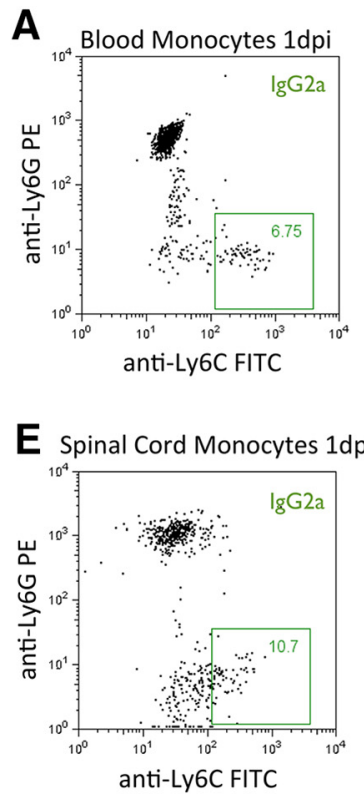
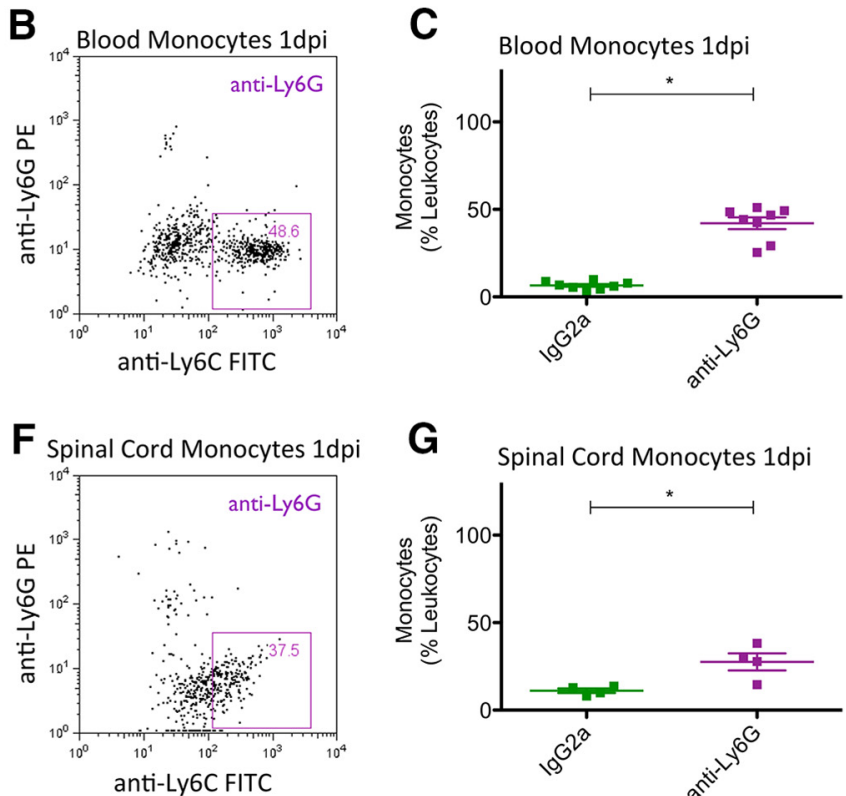
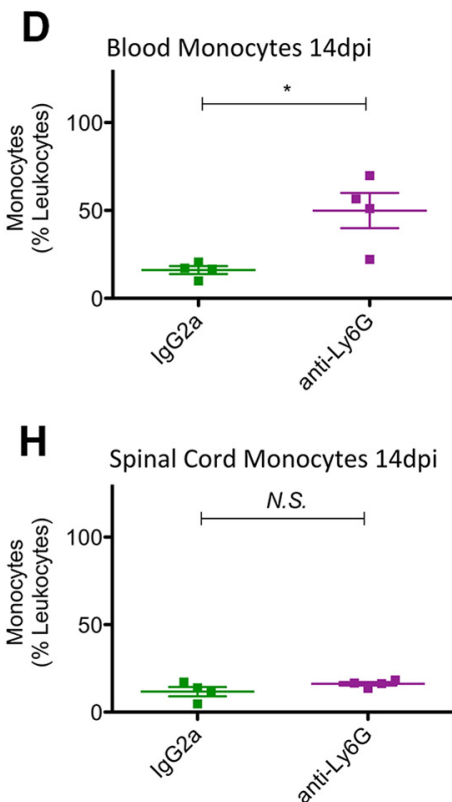

Figure 5. PMN depletion via anti-Ly6G increased the proportion of monocytes in the blood and spinal cord at 1 dpi and up to 14 dpi. $A, B, E, F$, Representative dot plots demonstrated an increased percentage of monocytes in blood $(\boldsymbol{A}, \boldsymbol{B})$ and spinal cords $(\boldsymbol{E}, \boldsymbol{F})$ of anti-Ly6G-treated animals (purple box), compared with that of lgG2a-treated animals (green box) at $1 \mathrm{dpi}$. $\boldsymbol{C}, \boldsymbol{D}, \boldsymbol{G}, \boldsymbol{H}$, Flow cytometric data analysis demonstrated that anti-Ly6G treatment increased the percentage of monocytes in blood at both $1 \mathrm{dpi}(\boldsymbol{C})$ and $14 \mathrm{dpi}(\boldsymbol{D})$, and in spinal cord at $1 \mathrm{dpi}(\boldsymbol{G})$ but not at $14 \mathrm{dpi}(\boldsymbol{H})$ when PMNs are known to be minimally detectable in the cord. Blood cells $(N=8 / \mathrm{group}$ at $1 \mathrm{dpi} ; N=4 /$ group at $14 \mathrm{dpi})$ and spinal cord cells $(N=4 / \mathrm{group}$ at 1 and $14 \mathrm{dpi})$ were immunolabeled for CD45, CD11b, Ly6G, and Ly6C. For all samples, the CD45 ${ }^{+} / \mathrm{CD}_{11 \mathrm{~b}}{ }^{+}$leukocyte cell population was gated to assess Ly6 $\mathrm{G}^{-} / \mathrm{Ly}_{6 \mathrm{C}}{ }^{+}$monocytes. Monocyte counts are expressed as a proportion (\%) of $\mathrm{CD} 45^{+} / \mathrm{CD} 11 \mathrm{~b}{ }^{+}$leukocytes. ${ }^{*} p<0.05$, Student's $t$ test. Values are given as the mean \pm SEM.
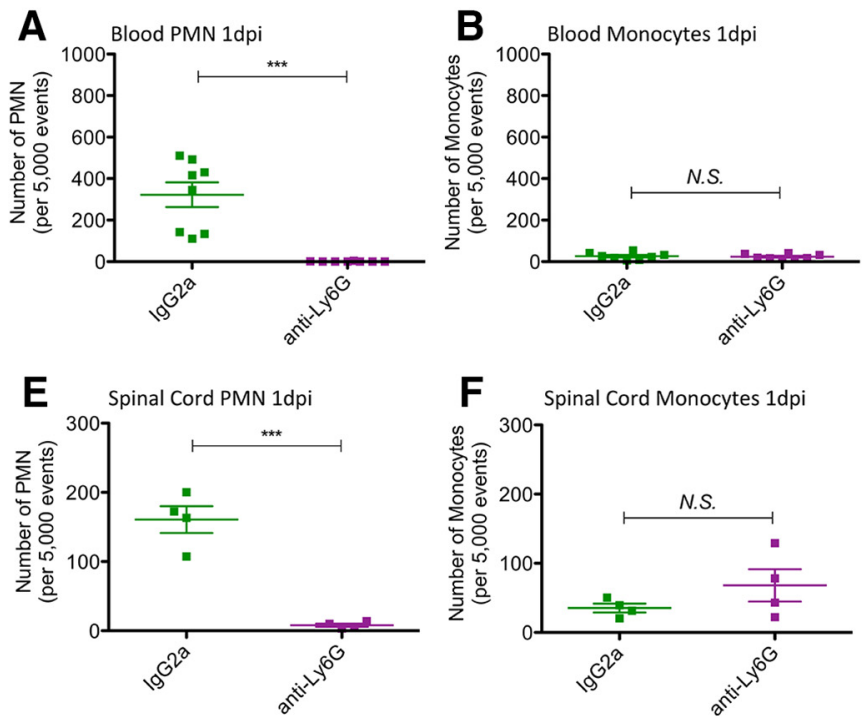
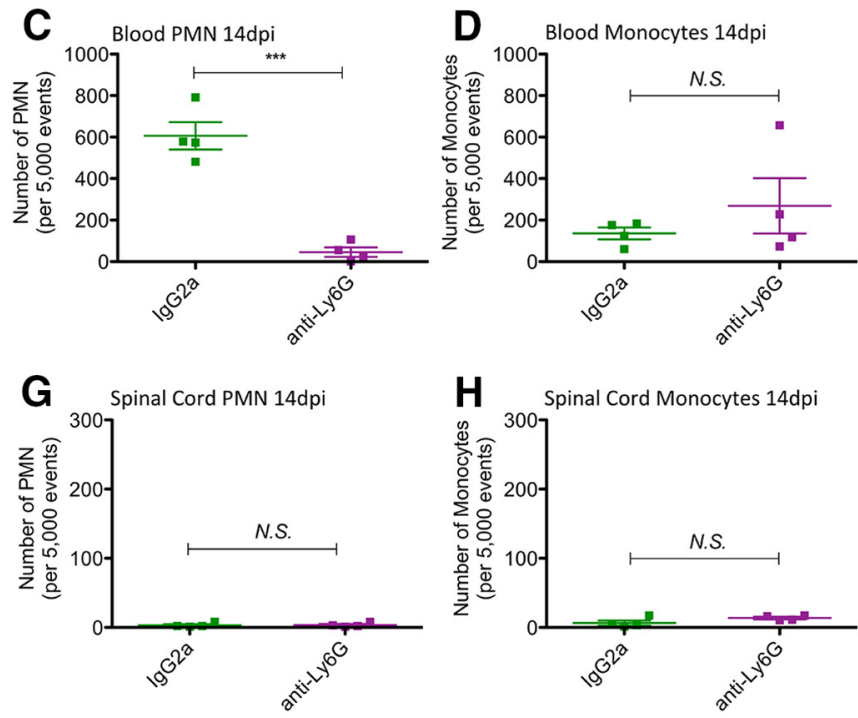

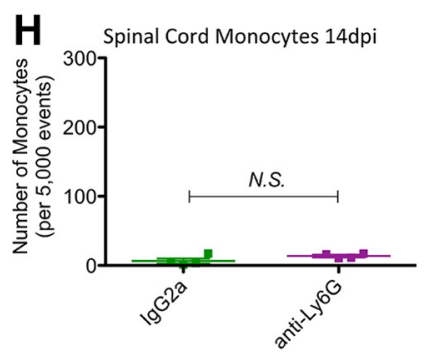

Figure 6. PMN depletion via anti-Ly6G did not affect the absolute number of monocytes in the blood and spinal cord at $1 \mathrm{dpi}$ and up to $14 \mathrm{dpi}$. The quantitation of PMN cell numbers per 5000 events demonstrated that anti-Ly6G treatment effectively depleted the number of PMNs (compared with lgG2a treatment) in blood at $1 \mathrm{dpi}(\boldsymbol{A})$ and $14 \mathrm{dpi}(\boldsymbol{C})$, and in the spinal cord at $1 \mathrm{dpi}(\boldsymbol{E})$, but not at $14 \mathrm{dpi}(\boldsymbol{G})$ when PMNs are known to be minimally detectable in the cord. $\boldsymbol{B}, \boldsymbol{D}, \boldsymbol{F}, \boldsymbol{H}$, Interestingly, the quantitation of monocyte cell numbers per 5000 events demonstrated no difference in the absolute number of monocytes between IgG2a- and anti-Ly6G-treated animals in the blood $(\boldsymbol{B}, \boldsymbol{D})$ and spinal cord $(\boldsymbol{F}, \boldsymbol{H})$ at either 1 or $14 \mathrm{dpi}$. Blood cells $(N=8 / \mathrm{group}$ at $1 \mathrm{dpi} ; N=4 / \mathrm{group}$ at $14 \mathrm{dpi}$ ) and spinal cord cells ( $N=4$ /group at 1 and $14 \mathrm{dpi}$ ) were immunolabeled for CD45, CD11b, Ly6G, and Ly6C, and were assessed for PMN or monocyte cell number per 5000 events via flow cytometry. For all samples, the $\mathrm{CD}_{4} 5^{+} / \mathrm{CD} 11 \mathrm{~b}^{+}$leukocyte cell population was gated to assess for $\mathrm{Ly} 6 \mathrm{G}^{+} / \mathrm{Ly}_{6 \mathrm{C}}{ }^{-} \mathrm{PMN}$ or $\mathrm{Ly} 6 \mathrm{G}^{-} / \mathrm{Ly}_{6 \mathrm{C}}{ }^{+}$monocytes. All values are expressed as the absolute number of PMNs or monocytes per 5000 events. ${ }^{* *} p<0.001$, Student's $t$ test. Values are given as the mean \pm SEM.

diately after SCI, mice also received bilateral hCNS-SCns transplants or vehicle into the spared parenchyma $1 \mathrm{~mm}$ above and below the SCI epicenter, as described above. Blood was collected to confirm PMN depletion efficiency at 1 and 14 dpi. All animals were sacrificed at 90 dpi (Fig. 8A). Figure 8 shows the results of groups that received cell transplant (open circles) and vehicle injection (filled squares), for both IgG2a (green) and anti-Ly6G (purple) groups, in the same graphs for reference. No significant differences were detected between groups that received cells versus vehicle within either the IgG2a or Ly6G treatment groups, demonstrating that cell transplantation did not alter the cellular response within animals that received IgG2a or anti-Ly6G.

Compared with the robust PMN levels in IgG2a-treated animals, complete PMN $\left(\mathrm{Ly}_{6 \mathrm{G}}{ }^{+} / \mathrm{Ly}_{6 \mathrm{C}}{ }^{-}\right)$depletion was evident 
A

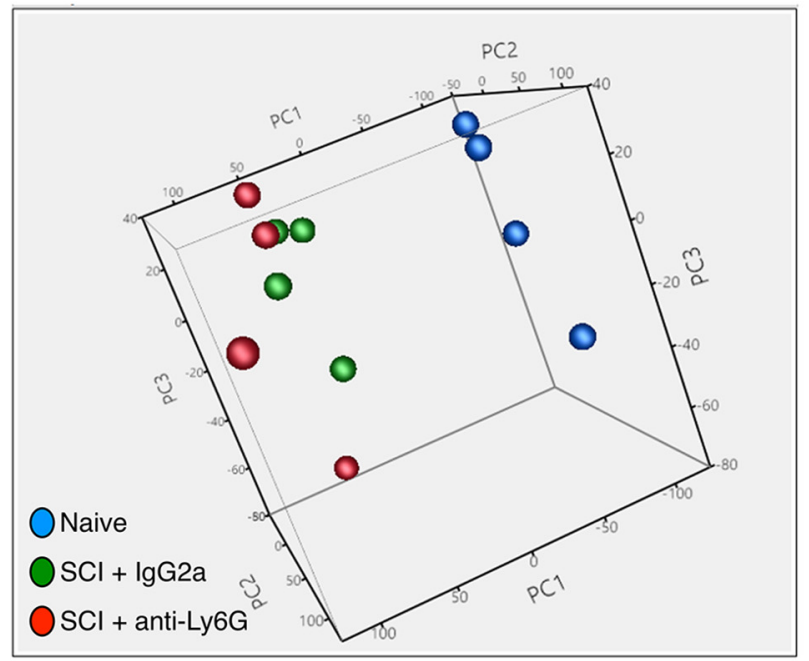

C

\begin{tabular}{rlrrrr}
\hline Gene Symbol & logFC & logCPM & LR & PValue & FDR \\
\hline Cxcl1 & 2.25 & 2.39 & 67.09 & $2.59 \mathrm{E}-16$ & $4.05 \mathrm{E}-12$ \\
Srgn & 1.14 & 5.28 & 56.42 & $5.85 \mathrm{E}-14$ & $4.57 \mathrm{E}-10$ \\
Il6 & 1.93 & 1.72 & 41.82 & $1.00 \mathrm{E}-10$ & $5.22 \mathrm{E}-07$ \\
Ccl9 & 1.39 & 5.14 & 35.05 & $3.21 \mathrm{E}-09$ & $1.26 \mathrm{E}-05$ \\
Ccr2 & 1.67 & 2.35 & 25.34 & $4.80 \mathrm{E}-07$ & $1.50 \mathrm{E}-03$ \\
Cxcl3 & 2.01 & 2.85 & 24.89 & $6.08 \mathrm{E}-07$ & $1.58 \mathrm{E}-03$ \\
Cxcr2 & -1.41 & 2.39 & 21.70 & $3.18 \mathrm{E}-06$ & $7.10 \mathrm{E}-03$ \\
Ppef1 & 2.19 & 0.98 & 19.68 & $9.17 \mathrm{E}-06$ & $1.74 \mathrm{E}-02$ \\
Plac8 & 2.07 & 0.96 & 19.51 & $1.00 \mathrm{E}-05$ & $1.74 \mathrm{E}-02$ \\
Ccl2 & 0.83 & 5.37 & 18.94 & $1.35 \mathrm{E}-05$ & $1.87 \mathrm{E}-02$ \\
Thbs1 & 1.67 & 7.46 & 18.91 & $1.37 \mathrm{E}-05$ & $1.87 \mathrm{E}-02$ \\
F13a1 & 1.33 & 4.84 & 18.78 & $1.47 \mathrm{E}-05$ & $1.87 \mathrm{E}-02$ \\
Bst1 & 1.4 & 2.21 & 18.67 & $1.56 \mathrm{E}-05$ & $1.87 \mathrm{E}-02$ \\
Ccl5 & 1.66 & 0.89 & 17.84 & $2.40 \mathrm{E}-05$ & $2.63 \mathrm{E}-02$ \\
Ms4a8a & 2.02 & 0.55 & 17.75 & $2.52 \mathrm{E}-05$ & $2.63 \mathrm{E}-02$ \\
Gpr35 & 0.97 & 3.04 & 17.45 & $2.95 \mathrm{E}-05$ & $2.88 \mathrm{E}-02$ \\
Mett17a1 & -0.65 & 3.97 & 16.96 & $3.81 \mathrm{E}-05$ & $3.42 \mathrm{E}-02$ \\
Lyn & 0.75 & 4.54 & 16.90 & $3.94 \mathrm{E}-05$ & $3.42 \mathrm{E}-02$ \\
Scn10a & 3.86 & 2.24 & 16.36 & $5.25 \mathrm{E}-05$ & $4.14 \mathrm{E}-02$ \\
Col24a1 & 1.16 & 2.14 & 16.34 & $5.30 \mathrm{E}-05$ & $4.14 \mathrm{E}-02$ \\
Csf3r & -1.02 & 4.05 & 16.03 & $6.24 \mathrm{E}-05$ & $4.51 \mathrm{E}-02$ \\
Fermt3 & 0.82 & 4.31 & 15.99 & $6.35 \mathrm{E}-05$ & $4.51 \mathrm{E}-02$ \\
Ifi214 & 1.83 & 0.56 & 15.86 & $6.82 \mathrm{E}-05$ & $4.63 \mathrm{E}-02$ \\
Fxyd2 & 2.93 & 1.79 & 15.67 & $7.53 \mathrm{E}-05$ & $4.86 \mathrm{E}-02$ \\
Rimkla & -0.53 & 5.60 & 15.61 & $7.78 \mathrm{E}-05$ & $4.86 \mathrm{E}-02$ \\
\hline & & & & &
\end{tabular}

\section{E}

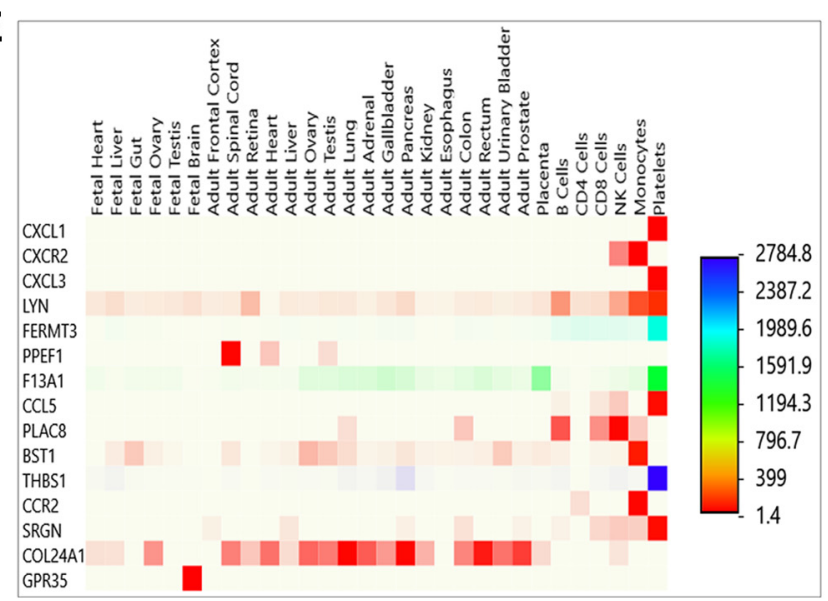

B
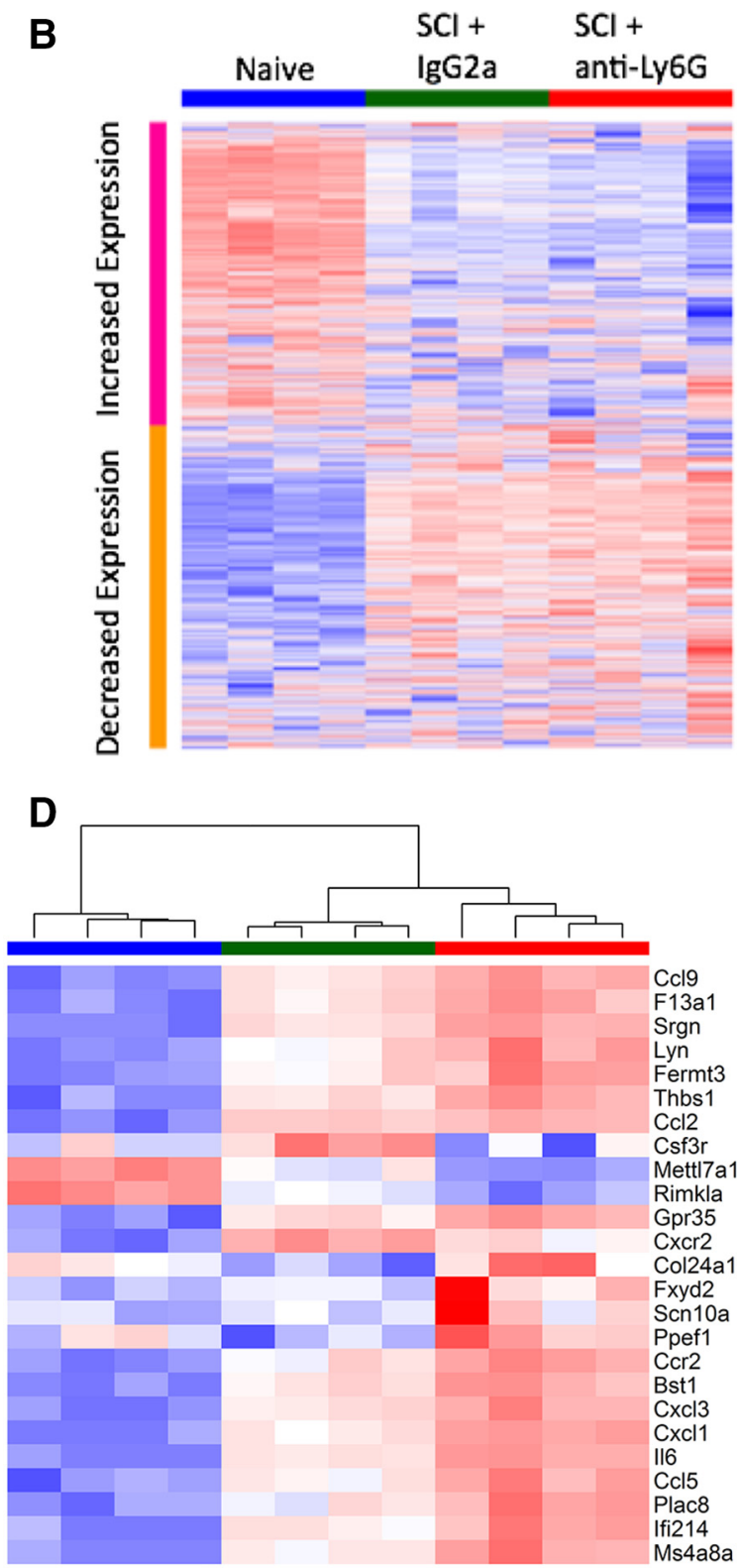

$\mathbf{F}$

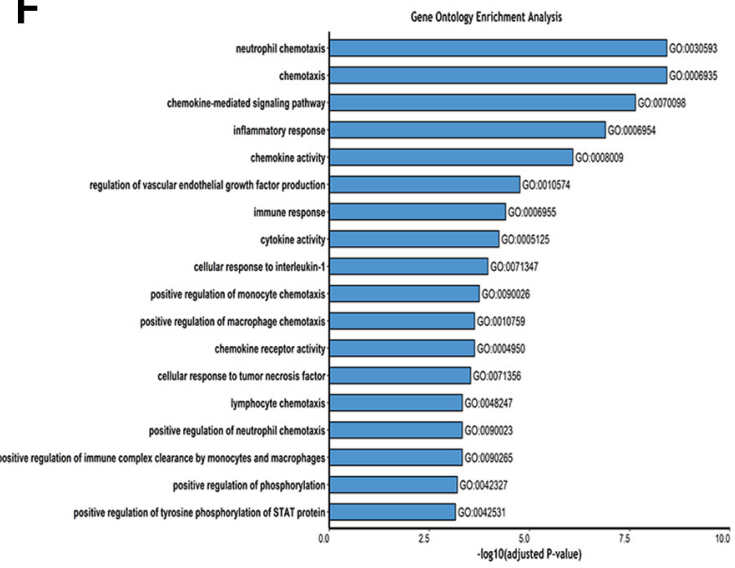

Figure 7. PMN depletion via anti-Ly6G altered gene expression associated with inflammation and cell fate in the spinal cord. All NOD-scid mice received a moderate (50 kilodyn) contusion injury at T9. Anti-Ly6G or lgG2a was administered intraperitoneally to mice as described above, and they were sacrificed at 1 dpi. Total RNAs from anti-Ly6G-treated $(N=4), \lg G 2 a-t r e a t e d ~(N=4)$, and naive $(N=4)$ mice were isolated from spinal cord tissues (T8-T10), and gene expression analysis was compared between naive and SCl lgG2a, naive and SCl anti-Ly6G, and SCl lgG2a and SCI anti-Ly6G groups. A, PCA was performed on the whole gene expression matrix of all samples. Each dot in the graph represents a sample color coded by experimental group (Figure legend continues.) 
in anti-Ly6G-treated animals at both 1 dpi (Fig. $8 B-D$ ) and 14 dpi (Fig. $8 E$ ). As above, an increased proportion of monocytes (Ly6G ${ }^{-} /$ Ly6 $\mathrm{C}^{+}$) was detected in blood at 1 and 14 dpi (Fig. $\left.9 A-D\right)$, and the specificity of PMN depletion by anti-Ly6G was confirmed by quantification of the absolute number of PMNs or monocytes per 5000 events counted via flow cytometry (Fig. 9E-H).

Lesion volume and astroglial scar formation after SCI are reportedly unaltered by treatment with anti-Ly6G (Saiwai et al., 2013). As a necessary step for histological comparisons of cell engraftment, we confirmed that anti-Ly6G treatment did not alter histological lesion volume in groups receiving cell transplants or vehicle as assessed by fibronectin volume 90 dpi (Fig. 10A, $B$; hCNS-SCns + IgG2a $=0.14 \pm 0.02 \mathrm{~mm}^{3}$; hCNS-SCns + antiLy6G $=0.13 \pm 0.02 \mathrm{~mm}^{3}$; Student's $t$ test, $p=0.49$ ). Accordingly, blinded unbiased stereological analysis of humanspecific hCNS-SCns engraftment was conducted via immunohistochemistry for the human-specific cytoplasmic marker SC121 to determine whether treatment with anti-Ly6G altered donor human cell number, localization, or lineage selection.

\section{Anti-Ly6G modulated localization but not total donor human cell engraftment after SCI}

Stereological analysis was conducted as described in Materials and Methods using the optical fractionator probe and contour definitions to identify the perimeter of the spinal cord and the spared spinal cord parenchyma. This analysis represents an unbiased and density/volume-adjusted estimate of the total number of engrafted donor human cells within the anatomical region sampled. Cell engraftment was observed in 100\% of hCNS-SCns + $\operatorname{IgG2a}(N=12)$ and hCNS-SCns + anti-Ly6G-treated $(N=12)$ animals. A subset of animals was randomly selected from each group for optical fractionator quantification of donor $\mathrm{SC} 121^{+}$ human cells and $\mathrm{SC}_{12} 3^{+}$human astrocytes $(N=5)$. The number of donor SC121 ${ }^{+}$human cells (Fig. 11A) showed no significant differences in engraftment between IgG2a- and anti-Ly6Gtreated groups 90 dpi (Fig. 11B; hCNS-SCns + IgG2a $=$ $654,500 \pm 55,050 ;$ hCNS-SCns + anti-Ly6G $=474,600 \pm$ 118,000 ; Student's $t$ test, $p=0.10$ ). However, dramatic differences were observed in the localization and distribution of donor

\section{$\leftarrow$}

(Figure legend continued.) and plotted in three dimensions using the first three principal components ( $P C 1-P(3)$. The analysis revealed a distinct cluster of the naive group (blue) and more similarities in the overall gene expression between the anti-Ly6G (red) and IgG2a (green) groups. B, Hierarchical clustering of the expression of 15,627 genes (rows) and samples (columns) ordered by experimental groups. Heatmap visualization of clustering revealed clear collections of genes that were systematically upregulated (red) or downregulated (blue) in naive and IgG2a or anti-Ly6G treatment groups, respectively. In contrast, there was an apparent similar gene expression pattern in lgG2a versus anti-Ly6G groups, substantiating PCA findings. C, The table listed 25 statistically significant genes (DE) found in lgG2a compared with anti-Ly6G groups by edgeR (logFC, log fold change; logCPM, log count per million; LR, likelihood ratio; Pvalue, unadjusted $p$ value; FDR, false discovery rate). $\boldsymbol{D}$, Heatmap of unsupervised bidirectional clustering of $25 \mathrm{DE}$ values of all samples indicated three distinct clusters classified by experimental group. Overall, 21 of the 25 DE genes were upregulated, and 4 genes ( $C x c r 2$, Mettl7a1, (sfr3, and Rimkla) were downregulated in a comparison of the anti-Ly6G- and IgG2a-treated groups. $\boldsymbol{E}$, Heatmap of tissue-specific expression for the significant genes was generated using Human Proteome Map (Kim et al., 2014) quantitative expression dataset implemented in Funrich 2.1.2. The magnitude of relative expression values across tissues was colored coded. The higher expression values were represented by an intense red color relative to the lower expression values. $\boldsymbol{F}$, The top significantly enriched $\mathrm{GO}$ terms associated with DEG are depicted in extended data Figure 7-1 available at https://10.1523/JNEUROSCI.2785-16.2017.f7-1. The $x$-axis of the bar graph indicated the $-\log 10$ scale of the $p$ values, and the $y$-axis designates $G 0$ term identifications and names. The lengths of the bars positively correlated with the statistical significance.
SC12 $1^{+}$human cells (Fig. 11C,D). While IgG2a-treated animals frequently exhibited dense clusters of SC121 ${ }^{+}$human cells in regions adjacent to the lesion epicenter (Fig. 11C; 3D reconstruction with lesion epicenter in red and $\mathrm{SC} 121^{+}$human cell clusters in blue in Fig. $11 c^{\prime}$ ), anti-Ly6G-treated animals exhibited either significantly smaller clusters or the absence of clustered cells entirely (Fig. 11D; 3D reconstruction with lesion epicenter in red and $\mathrm{SC} 121^{+}$human cell clusters in blue in Fig. 11 $d^{\prime}$ ). Accordingly, anti-Ly6G-treated animals exhibited a significant reduction in the number of $\mathrm{SC}_{12} 1^{+}$cells compared with IgG2a-treated animals in the spared tissue adjacent to the lesion (Fig. 11E). The density of $\mathrm{SC} 21^{+}$human cells in IgG2a-treated animals precluded accurate stereological sampling of individual cells, suggesting that the quantitative cell number comparison in Figure $11, B$ and $E$, represents an underestimation of donor human cells at these dense regions. We therefore confirmed this observation using unbiased stereological quantification of $\mathrm{SC} 21^{+}$human cell cluster volume (Fig. 11F), which also demonstrated that antiLy6G-treated animals exhibited a loss of donor human cell clustering near the lesion epicenter. Together, these data show that anti-Ly6G treatment altered the localization of donor human cells near the lesion site and suggest a novel role for PMNs in modulating donor human cell behavior in the SCI microenvironment.

\section{Anti-Ly6G inhibited astroglial differentiation of donor human hCNS-SCns proximal to the lesion epicenter}

As characterized above, clusters of donor human cells proximal to the lesion, in the region typically occupied by reactive astrocytes and associated with the glial scar post-SCI, are a key feature observed in an acute cell transplantation paradigm. Accordingly, human astrocyte lineage selection was assessed via immunohistochemistry for the human-specific anti-GFAP antibody SC123. Donor human cells proximal to the lesion epicenter in hCNSSCns + IgG2a-treated animals were predominantly SC123 ${ }^{+}$human astrocytes, with extensive accumulation in dense clusters (Fig. 12A; 3D reconstruction with lesion epicenter in red and SC123 ${ }^{+}$human astrocyte clusters in blue in Fig. $\left.12 a^{\prime}\right)$. In striking contrast, engrafted cells in hCNS-SCns + anti-Ly6G-treated animals were not retained in clusters, and few human astrocyte clusters were observed proximal to the lesion (Fig. 12B; 3D reconstruction with lesion epicenter in red and $\mathrm{SC}_{12} 3^{+}$human astrocyte clusters in blue in Fig. $12 b^{\prime}$ ).

Anti-Ly6G-mediated reduction of human astrocyte clusters near the lesion was supported by blinded unbiased stereological quantification of the total number of $\mathrm{SC}_{2} 23^{+}$human astrocytes using the optical fractionator probe, which demonstrated a significant decrease in hCNS-SCns + anti-Ly6G-treated animals compared with hCNS-SCns + IgG2a-treated animals (Fig. 12C; hCNS-SCns + anti-Ly6G $=23,980 \pm 8105$; hCNS-SCns + $\operatorname{IgG2a}=48,410 \pm 6955$; Student's $t$ test, $p<0.05$ ). Further analysis of the number of $\mathrm{SC} 123^{+}$human astrocytes localized to the region proximal versus distal to the epicenter revealed that this difference was specific to the region near the lesion (within $1 \mathrm{~mm}$ ) and not observed in regions away $(>1 \mathrm{~mm})$ from the lesion (Fig. 12D; Student's $t$ tests, $p<0.05$ near lesion, $p=0.28$ away from lesion). An associated decrease in the number of $\mathrm{SC} 123^{+}$human astrocytes was observed in the anti-Ly6G-treated animals when stereological data were plotted in a distribution curve (Fig. 12E; two-way ANOVA followed by Bonferroni post hoc $t$ tests, $p<0.001$ at the spared tissue region adjacent to the lesion). As was the case for SC121 quantification, the density of $\mathrm{SC} 23^{+}$cells near the lesion epicenter in IgG2a-treated animals was so high as to preclude accurate cell counting, resulting in a 
A

Vehicle or Blood PMN Cell Tx assessment

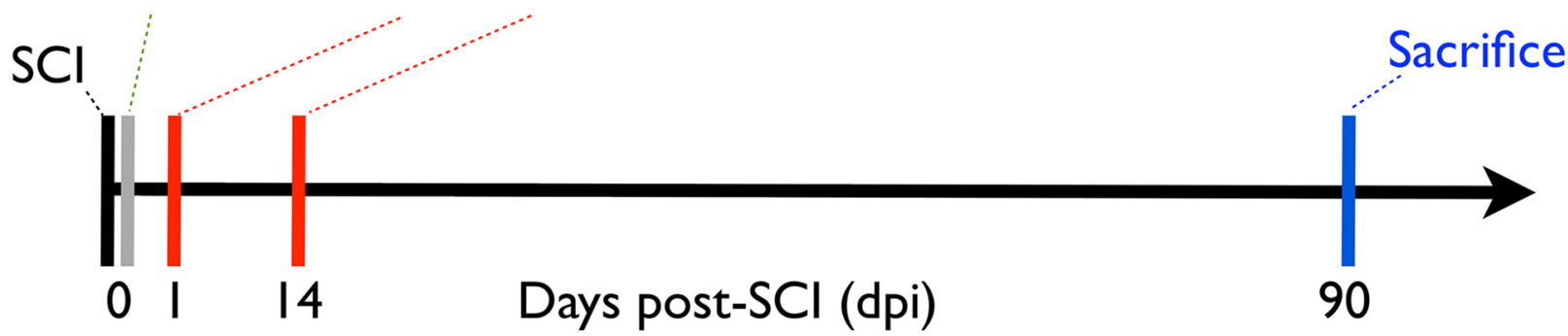

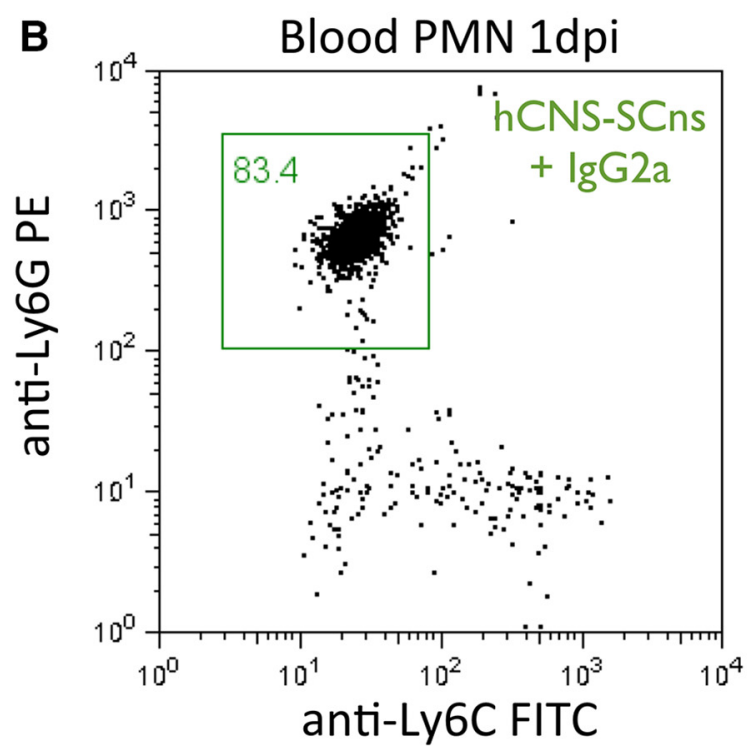

D Blood PMN 1dpi

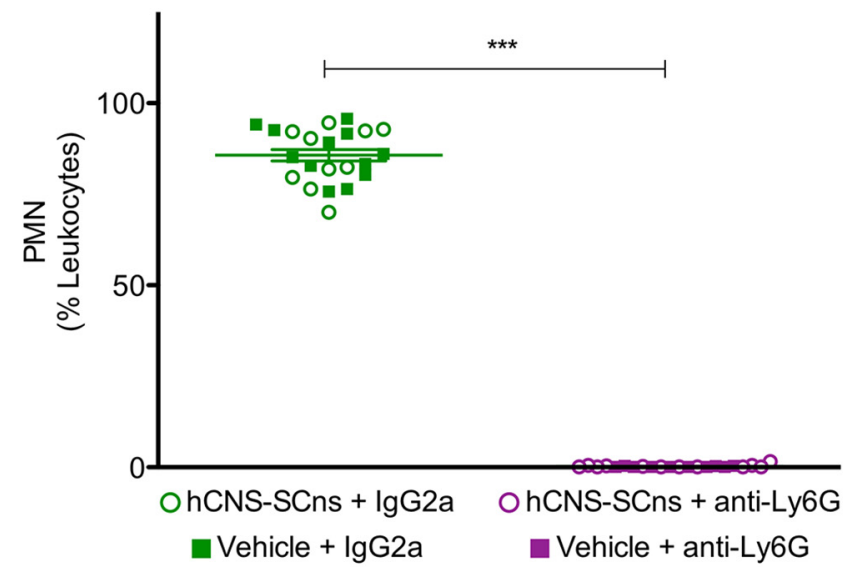

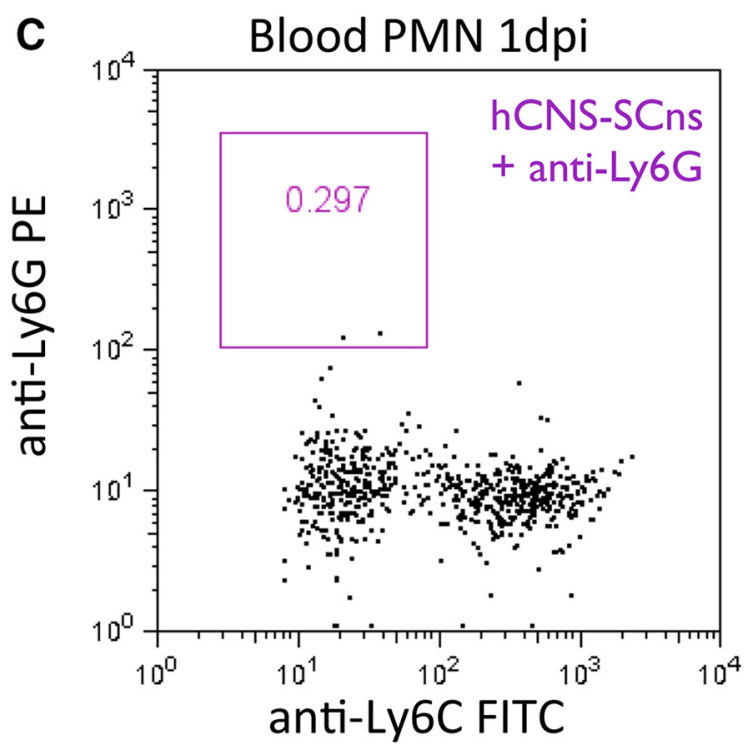

E Blood PMN 14dpi

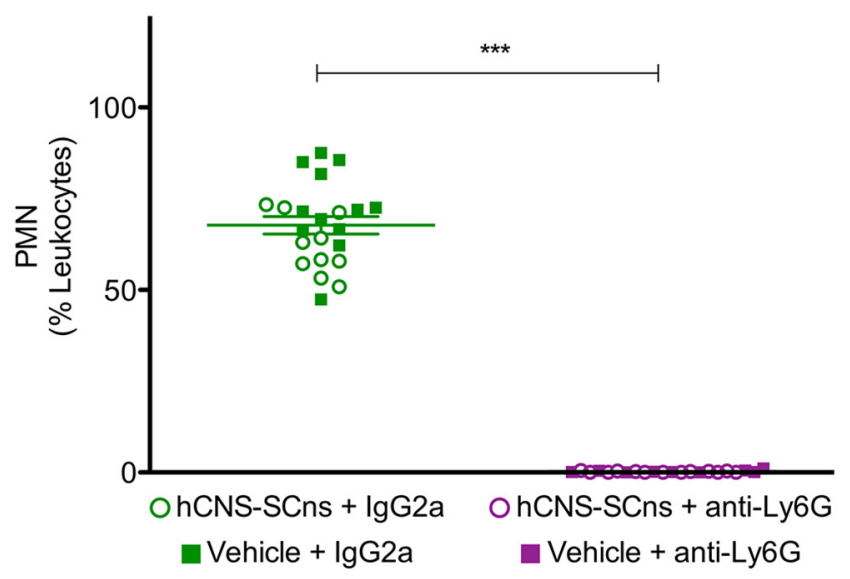

Figure 8. Anti-Ly6G depleted blood PMNs following hCNS-SCns transplantation at $1 \mathrm{dpi}$ and up to $14 \mathrm{dpi}$ after SCI. $A$, Immediately after SCl, animals receiving intraperitoneal injections of anti-Ly6G or lgG2a were transplanted with either hCNS-SCns (75,000/animal) or vehicle. Blood cells ( $N=10-12)$ were immunolabeled for CD45, CD11b, Ly6G, and Ly6C. The CD45 ${ }^{+} /$CD11b ${ }^{+}$ leukocyte cell population was gated to assess for Ly6G ${ }^{+} /$Ly6C ${ }^{-}$PMNs. B, C, hCNS-SCns + anti-Ly6G-treated but not hCNS-SCns + IgG2a-treated animals exhibited depletion of the PMN population in blood at 1 and 14 dpi. $\boldsymbol{D}, \boldsymbol{E}$, Animals that received hCNS-SCns (open circles) or vehicle injection (filled squares) for both IgG2a (green) and anti-Ly6G (purple) are shown in the same graph for reference. $\boldsymbol{D}$, No significant differences were detected in blood PMNs 1 dpi between groups that received cells versus vehicle in either lgG2a (hCNS-SCns $+\operatorname{lgG} 2 \mathrm{a}=85.3 \pm 2.6 \%$ vs vehicle + $\lg 2 \mathrm{a}=86.1 \pm 1.9 \% ; N=10-12$, Student's $t$ test, $p=0.80$ ) or anti-Ly6G (hCNS-SCns + anti-Ly6G $=0.21 \pm 0.11 \%$ vs vehicle + anti-Ly6G $=0.09 \pm 0.05 \% ; N=10-12$, Student's $t$ test, $p=0.43$ ) treatment groups. $\boldsymbol{E}$, Similarly, no significant differences were detected in blood PMNs 14 dpi between groups that received cells versus vehicle in either IgG2a (hCNS-SCns $+\operatorname{lgG2a}=$ $62.18 \pm 2.5 \%$ vs vehicle $+\operatorname{lgG} 2 \mathrm{a}=70.95 \pm 3.3 \% ; N=10-12$, Student's $t$ test, $p<0.05$ ) or anti-Ly6G (hCNS-SCns + anti-Ly6G $=0.1691 \pm 0.05 \%$ vs vehicle + anti-Ly6G $=0.2839 \pm 0.11 \%$; $N=10-12$, Student's $t$ test, $p=0.33$ ) treatment groups. ${ }^{* *} p<0.001$, Student's $t$ test. Values are given as the mean \pm SEM. 
A
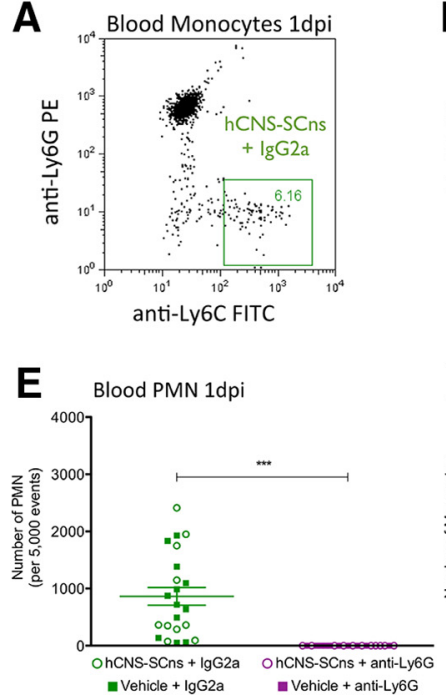

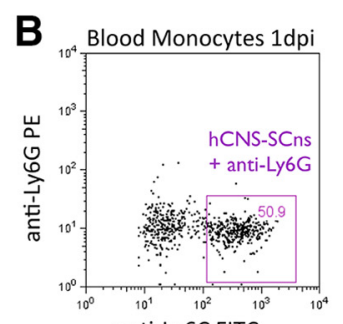

anti-Ly6C FITC

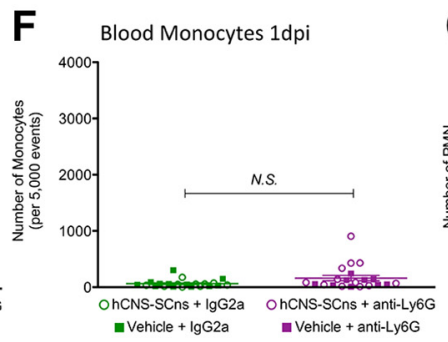

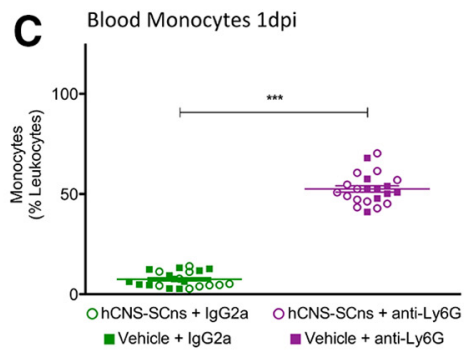

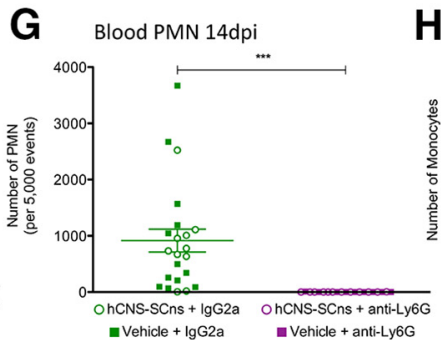

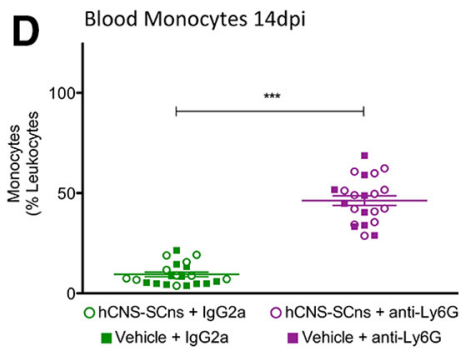

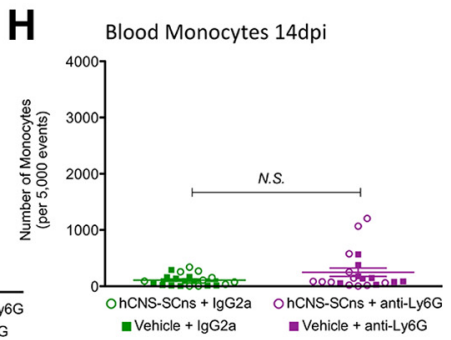

Figure 9. PMN depletion via anti-Ly6G increased the proportion of monocytes but did not affect the absolute number of blood monocytes at 1 dpi and up to 14 dpi following hCNS-SCns transplantation. $\boldsymbol{A}-\boldsymbol{D}, \mathrm{hCNS}-\mathrm{SCnS}+$ anti-Ly6G treatment $(\boldsymbol{B})$ had increased blood monocyte proportion at $1 \mathrm{dpi}$ compared with hCNS-SCns + IgG2a treatment $(\boldsymbol{A})$, demonstrating an increase in the percentage of monocytes in blood at $1 \mathrm{dpi}(\boldsymbol{C})$ and $14 \mathrm{dpi}(\boldsymbol{D}) . \boldsymbol{E}, \mathbf{G}$, Quantitation of PMN absolute cell numbers per 5000 events demonstrated that the hCNS-SCns + anti-Ly6G treatment group had depleted numbers of blood PMNs at $1 \mathrm{dpi}(\boldsymbol{E})$ and $14 \mathrm{dpi}(\boldsymbol{G}) . \boldsymbol{F}, \boldsymbol{H}$, In contrast, the quantitation of monocyte absolute cell number per 5000 events demonstrated no difference in the number of blood monocytes between hCNS-SCns + IgG2a and hCNS-SCns + anti-Ly6G groups at either $1 \mathrm{dpi}(\boldsymbol{F})$ or $14 \mathrm{dpi}(\boldsymbol{H})$. $\boldsymbol{C}-\boldsymbol{H}$, Quantitative flow cytometry results for groups that received injections with hCNS-SCns (open circles) or vehicle (filled squares) for both lgG2a (green) and anti-Ly6G (purple) in the same graphs for reference. No significant differences in the percentage or absolute number of PMNs or monocytes were detected between groups that received hCNS-SCns versus vehicle within either the lgG2a or anti-Ly6G treatment groups. $N=10-12^{\prime},{ }^{* * *} p<0.001$, Student's $t$ test. Values are given as the mean \pm SEM.

A

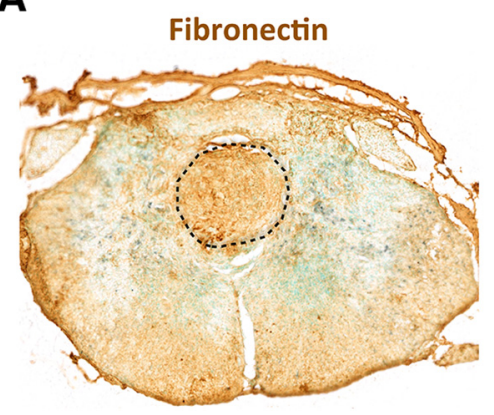

B

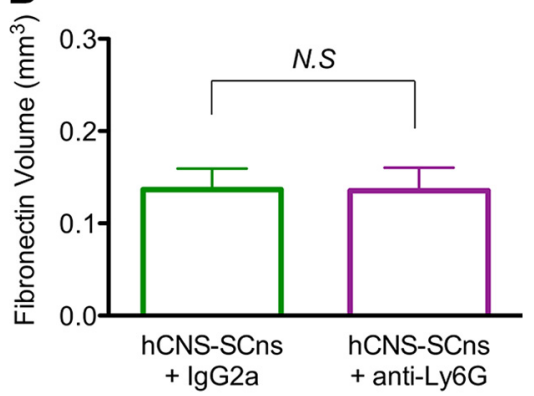

Figure 10. Anti-Ly6G did not alter fibronectin lesion volume following hCNS-SCns transplantation post-SCI. A, Spinal cord sections of animals that received IgG2a or anti-Ly6G following hCNS-SCns transplantation 12 weeks post-SCI were immunolabeled with fibronection to identify the lesion, which is marked by the dotted line. $\boldsymbol{B}$, Stereological quantification for the volume of the fibronectin ${ }^{+}$lesion demonstrated no significant differences between hCNS-SCns + lgG2a and hCNS-SCns + anti-Ly6G ( $N=5$ randomly selected animals/group, Student's $t$ test, $p=0.17)$. Scale bars, $250 \mu \mathrm{m}$. Values are given as the mean \pm SEM.

likely underestimate of SC123 ${ }^{+}$human astrocytes in this region. To provide a second measure and quantitatively assess cell clustering, the volume of SC123 clusters was also determined by stereology using the Calvalieri probe and sequentially revealed a significant reduction in anti-Ly6G-treated versus IgG2a-treated animals (Fig. 12F; $p<0.05$ ). In all, these data demonstrate a profound change in donor human cell distribution and astrocyte number/clustering in response to anti-Ly6G treatment, demonstrating a novel role for PMNs to modulate donor human cell lineage selection and distribution. Accordingly, we next assessed the impact of these fundamental changes in donor human cell localization and fate on functional locomotor recovery.

Anti-Ly6G restores the capacity of hCNS-SCns to promote the recovery of function after SCI

PMN infiltration has been suggested to exert a detrimental role post-SCI, and inhibition of early acute inflammation (up to sev- eral days post-SCI) has been shown to improve locomotor recovery (Tonai et al., 2001; Saville et al., 2004; Gorio et al., 2007; Bao et al., 2011); however, these studies were not PMN specific in depletion. In fact, only Saiwai et al. (2013) have tested the role of PMNs in SCI using a specific PMN depletion paradigm (Saiwai et al., 2013); in that study, PMN depletion up to 7 dpi with anti-Ly6G did not improve locomotor recovery in mice assessed through 42 dpi. Accordingly, we first sought to test whether anti-Ly6G treatment modulated long-term functional recovery after SCI (through $90 \mathrm{dpi}$ ) in our paradigm using NOD-scid mice, independent of hCNSSCns transplant. To address this question, mice received vehicle instead of hCNS-SCns transplants and were assessed for locomotor recovery of function using CatWalk kinematic gait analysis. Consistent with Saiwai et al. (2013), mice that received vehicle + IgG2a versus vehicle + anti-Ly6G in our paradigm exhibited no significant change in hindpaw print area, hindpaw maximum contact area, mean swing speed, and the percentage of step sequence Abs (Fig. $13 A-D)$. These data suggest that early PMN infiltration does not exert dramatic effects on long-term recovery of function after SCI.

Although PMN depletion with anti-Ly6G did not alter locomotor performance in animals that received vehicle, animals that received donor cell transplants exhibited improved locomotor recovery in CatWalk kinematic analysis, including the restoration of hindpaw print area (Fig. 13A), hindpaw maximum contact area (Fig. 13B), mean swing speed (Fig. 13C), and the percentage of step sequence Abs (Fig. 13D) when normalized to preinjury levels (Fig. 13D, dotted line indicates preinjury performance normalization to $100 \%$ for each parameter; one- 
A SC121 Human Cells

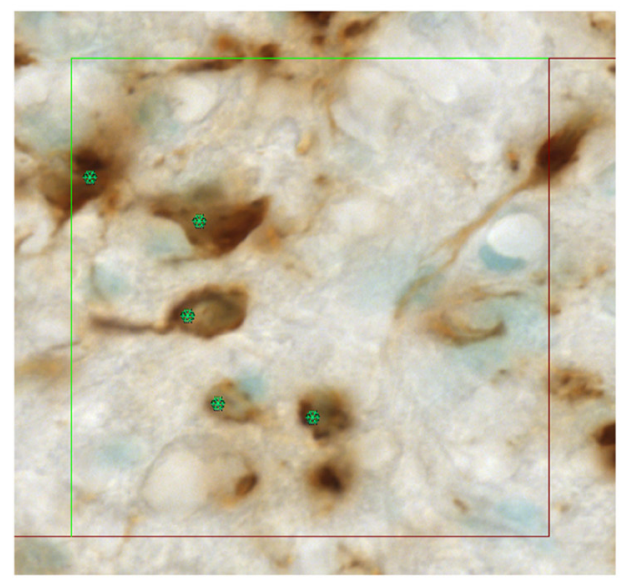

C hCNS-SCns + IgG2a

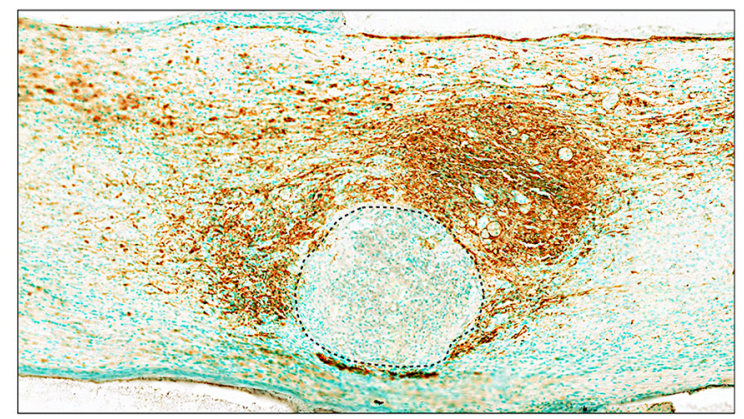

$c^{\prime}$

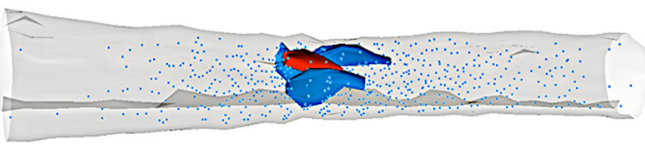

E

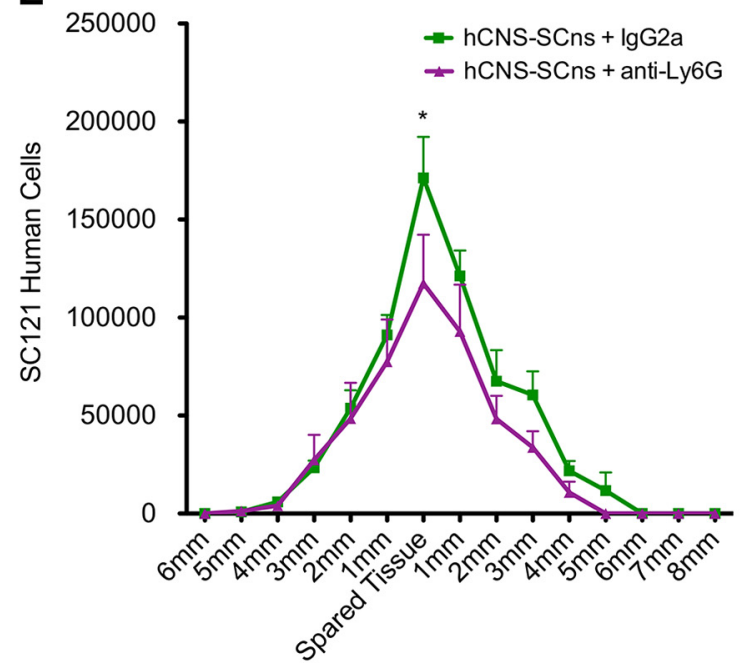

B

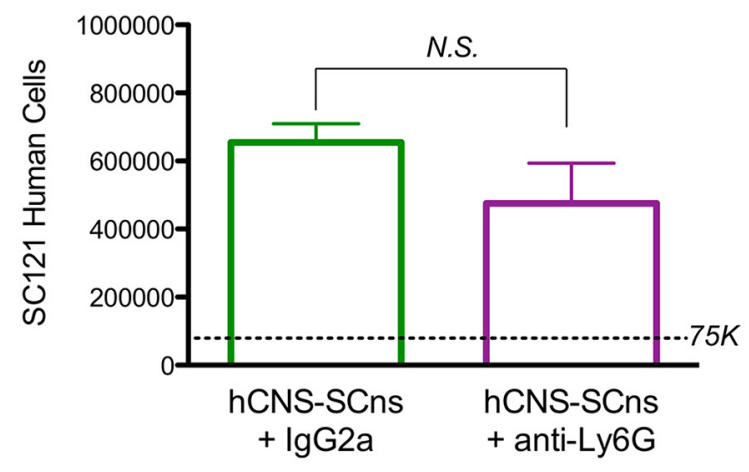

D hCNS-SCns + anti-Ly6G

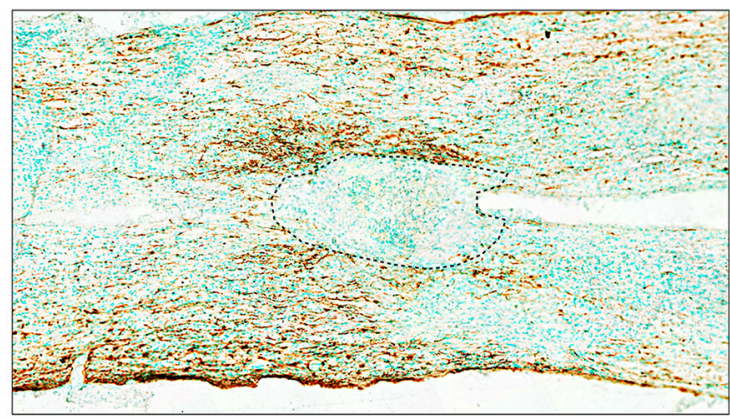

d'

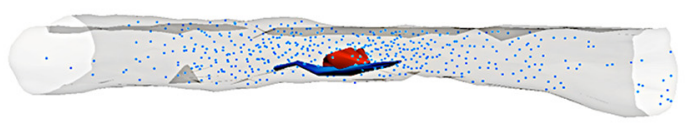

$\mathbf{F}$

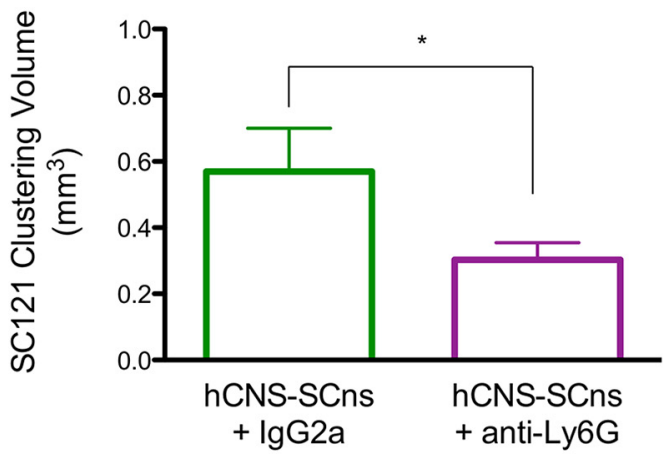

Figure 11. Anti-Ly6G did not alter human cell engraftment but did reduce human cell localization and cluster volume near the lesion epicenter. $A$, Human-specific SC121 cells (brown) detected hCNS-SCns survival at 12 weeks post-SCI. Nuclei were identified by methyl green counterstain (green). B, Stereological quantification of human cells revealed no difference in cell engraftment between hCNS-SCns + IgG2a and hCNS-SCns + anti-Ly6G groups $(N=5$; Student's ttest, $p=0.10)$. The dashed line indicates the original transplant dose of 75,000 cells. C, hCNS-SCns $+\operatorname{lgG} 2$ a treatment resulted in dense clusters of $\mathrm{SC} 121^{+}$donor human cells (brown) near the lesion epicenter (marked by dashed border), which is consistent with the data from Figure 1A.D, In contrast, in hCNS-SCns + anti-Ly6G mice, a dispersed distribution of $\mathrm{SC} 121^{+}$cells was apparent. $\boldsymbol{c}^{\prime}, \boldsymbol{d}^{\prime}$, Three-dimensional reconstructions generated by stereological quantification of the lesion (red), $S \mathrm{~S}\left(121^{+}\right.$clusters (blue), and individual $\mathrm{SC} 121^{+}$cells. E, Stereological quantification of SC121 ${ }^{+}$cells revealed a reduction of $S \mathrm{C} 121^{+}$cell numbers in the spared tissue adjacent to the lesion in hCNS-SCns + anti-Ly6G-treated animals, compared with that of hCNS-SCns + IgG2a-treated animals ( $N=5$; two-way ANOVA with Bonferroni post hoc t test, $p<0.05)$. $\boldsymbol{F}$, Additional analysis of SC121 ${ }^{+}$volume near the lesion of hCNS-SCns + anti-Ly6G-treated animals revealed a significant reduction in comparison with hCNS-SCns + lgG2a-treated animals $(N=5$; Student'st test, $p<0.05)$. Values are given as the mean \pm SEM. 
A hCNS-SCns + IgG2a

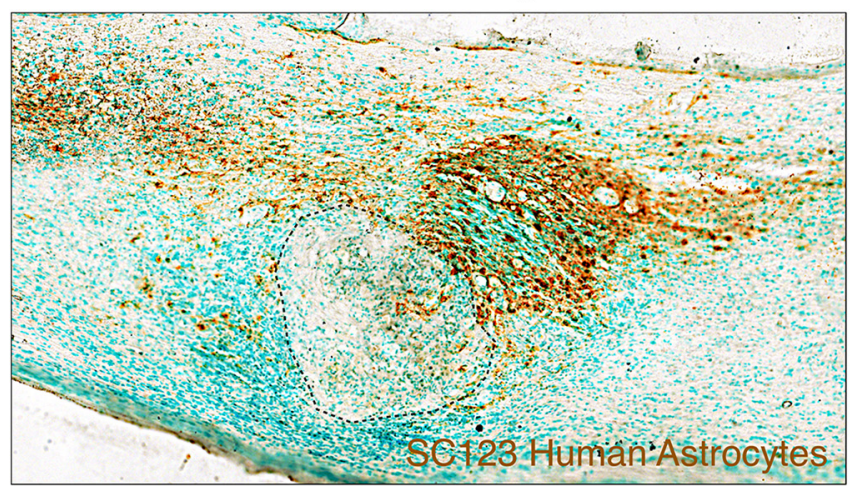

$a^{\prime}$

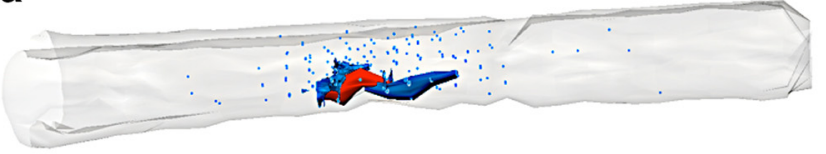

C

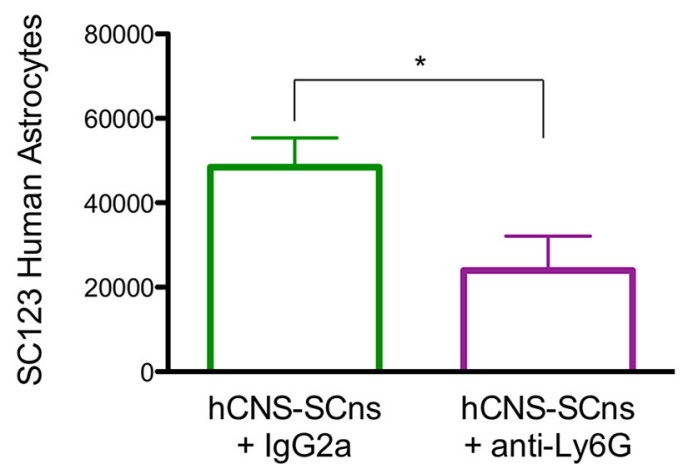

E

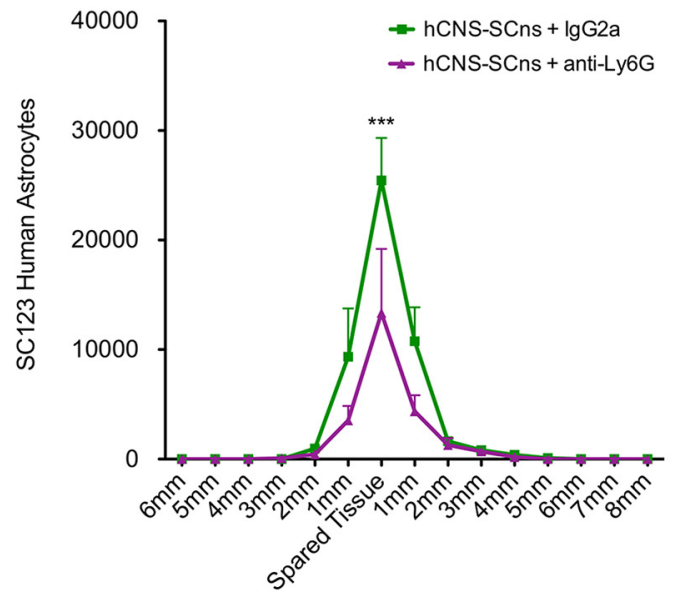

B hCNS-SCns + anti-Ly6G

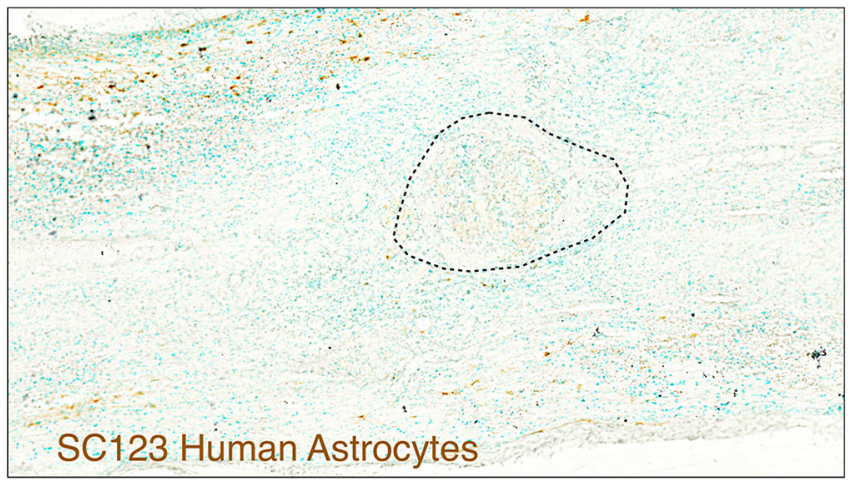

b'

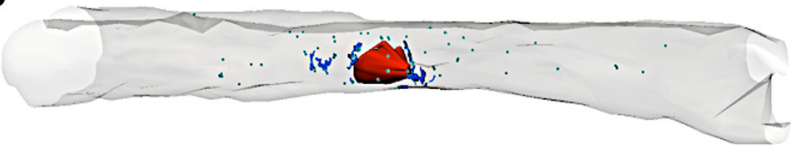

D

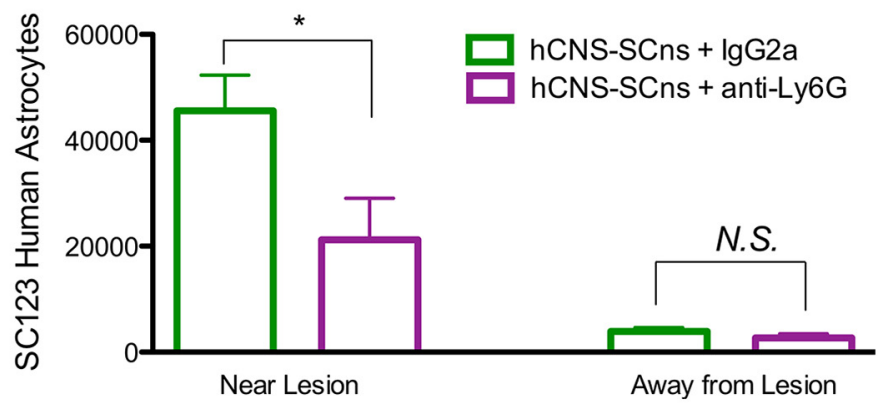

$\mathbf{F}$

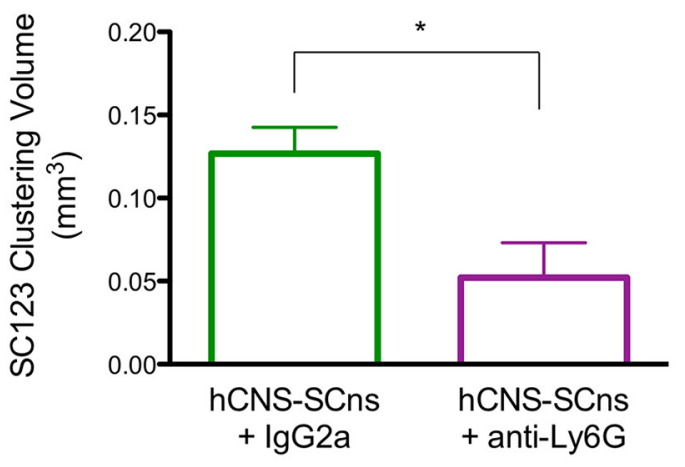

Figure 12. Anti-Ly6G inhibited human astroglial differentiation and human astrocyte localization near the SCl epicenter. $\boldsymbol{A}$, In hCNS-SCns + IgG2a-treated animals, a dense cluster of human-specific astrocytes (SC123; brown) was observed near the lesion (dashed border). $\boldsymbol{B}$, In contrast, hCNS-SCns + anti-Ly6G-treated animals exhibited robust reduction of SC123 ${ }^{+}$cells near

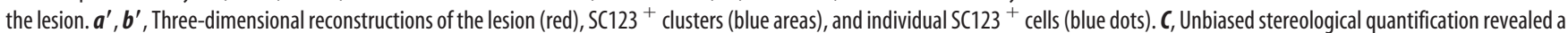
significant reduction in the number of SC123 ${ }^{+}$cells in hCNS-SCns + anti-Ly6G vs hCNS-SCns + IgG2a-treated animals ( $N=5$; Student's $t$ test, $\left.p<0.05\right)$. D, Analysis of the number of SC123 ${ }^{+}$ cells near the lesion (1 mm rostral and caudal to epicenter) vs away from the lesion ( $>1 \mathrm{~mm}$ distal to epicenter) revealed that changes in the number of $S C 123{ }^{+}$cells were restricted to regions near the lesion $(N=5$; Student's $t$ test, $p<0.05)$ and that there was no compensatory increase of $S C 123+$ cell number in distal regions $(N=5 ;$ Student's $t$ test, N.S. $=p>0.05)$. $\boldsymbol{E}$, Stereology also revealed a significant reduction in the number of SC123 ${ }^{+}$cells within spared tissue (proximal to lesion) of hCNS-SCns + anti-Ly6G vs hCNS-SCns + IgG2a-treated animals ( $N=5$; tw0-way ANOVA with Bonferroni post hoc $t$ tests, $p<0.001)$. F, The SC123 ${ }^{+}$cells volume near the lesion of hCNS-SCns + anti-Ly6G-treated animals was significantly less than that in hCNS-SCns + IgG2a-treated animals $(N=5$; Student's $t$ test, $p<0.05)$. Values are given as the mean \pm SEM. 

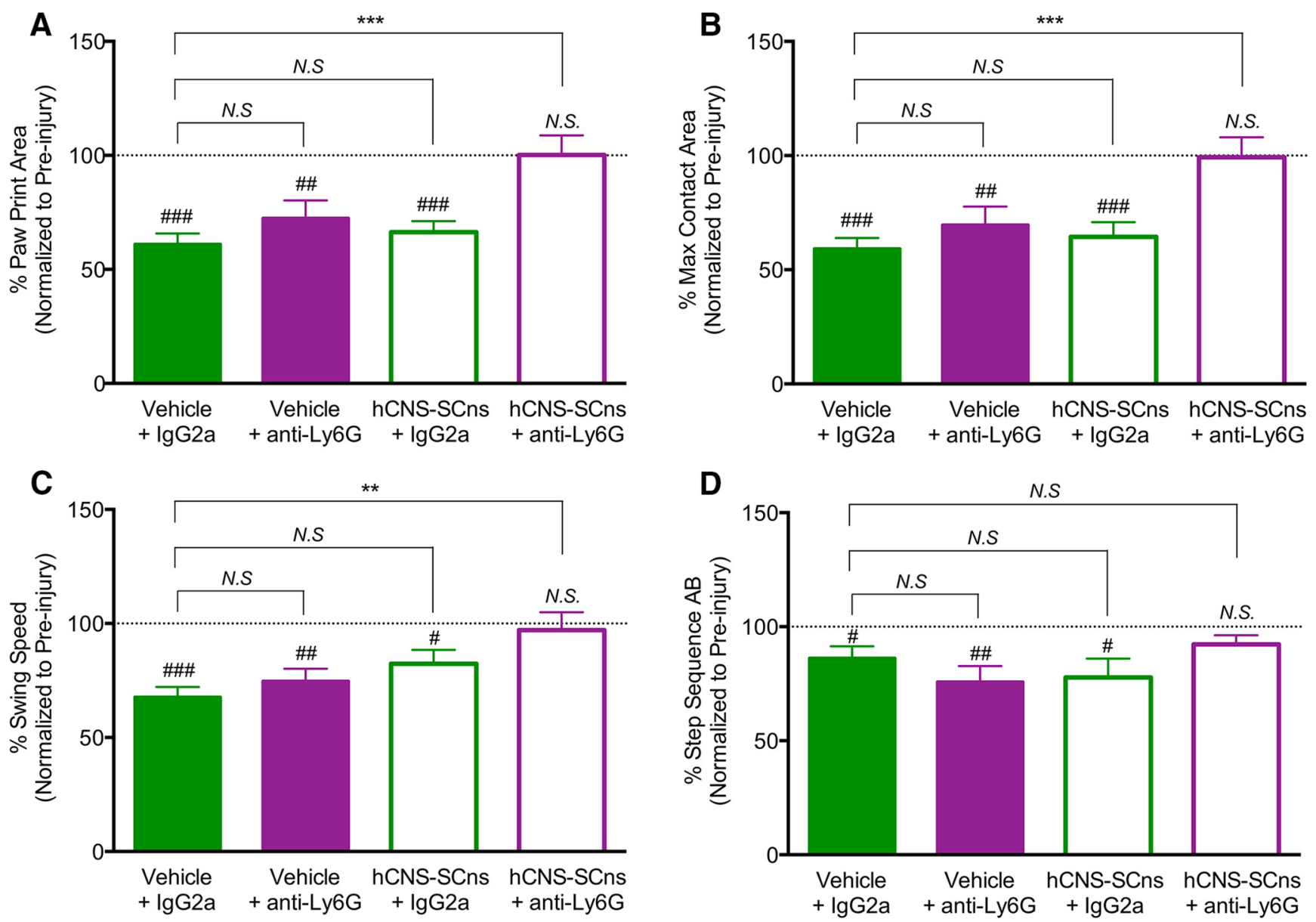

Figure 13. Anti-Ly6G improved functional recovery in mice with hCNS-SCns transplantation at 12 weeks post-SCI. Recovery of function was assessed at 12 weeks post-SCI by multiple measures of CatWalk analysis. $\boldsymbol{A}-\boldsymbol{D}$, Compared with the normalized preinjury levels from all animals (dotted lines), animals that received vehicle $+\operatorname{lgG} 2 \mathrm{~g}$, vehicle + anti-Ly6G, and hCNS-SCns + IgG2a had significant decrements in the paw print area percentage $(\boldsymbol{A})$, maximum contact area percentage $(\boldsymbol{B})$, mean swing speed percentage $(\boldsymbol{C})$, and step sequence $\mathrm{Ab}$ percentage $(\boldsymbol{D})$ at 12 weeks post-SCI. However, only animals that received hCNS-SCns + anti-Ly6G showed no difference (N.S. $=p>0.05$ ) to normalized preinjury levels of all measures of CatWalk, demonstrating that anti-Ly6G rescued the capacity of hCNS-SCns to improve functional recovery. $N=10-12$; one-sample column $t$ test, $\# p<0.05$, \#\#p $<0.01$, \#\#\# $<0.001$. Alternately, normalized measured values of vehicle + IgG2a-treated animals were also compared with all other animal groups. Critically, only animals that recieved hCNS-SCns + anti-Ly6G had significant improvement in paw print area percentage $(\boldsymbol{A})$, maximum contact area percentage $(\boldsymbol{B})$, and mean swing speed percentage $(\boldsymbol{C})$. All values were normalized to the levels of preinjury animals (dotted lines). $N=10-12 ;$ one-way ANOVA followed by Dunnett post hoc $t$ tests, ${ }^{* *} p<0.01,{ }^{* * *} p<0.001$. Values are given as the mean $\pm \mathrm{SEM}$.

sample $t$ test, N.S. indicates performance equivalent to preinjury baseline, \# indicates $p<0.05$ in comparison with preinjury baseline, \#\# indicates $p<0.01$, \#\#\# indicates $p<0.001$ in comparison with preinjury baseline). In addition, only mice receiving antiLy6G in combination with hCNS-SCns exhibited improved functional recovery in comparison with Vehicle + IgG2a control (Fig. $13 A-C$, ANOVA followed by post hoc Dunnett's $t$ test, ${ }^{* *}$ indicates $p<0.01,{ }^{* *}$ indicates $\left.p<0.001\right)$. Together, these data demonstrate a novel role for PMNs in the modulation of donor hNSCmediated locomotor improvements after SCI. This link between donor hNSC distribution/fate and the recovery of function demonstrates the potential for the optimization of cell therapy by manipulating the cellular inflammatory response to alleviate CNS injuries or diseases.

\section{Discussion}

Cell-based approaches for the treatment of CNS trauma and SCI have provided proof of concept for locomotor improvement in animal models (Nakamura and Okano 2013; Liu et al., 2000; Cummings et al., 2005; Keirstead et al., 2005; Karimi-Abdolrezaee et al., 2006; Martino and Pluchino 2006; Parr et al., 2008). Transplan- tation studies have generally presumed that the acute injury microenvironment is too toxic to permit donor cell engraftment (Okano 2002) and, therefore, focused on the subacute and chronic phases of trauma. Critically, we report that total donor human cell engraftment is not affected by time of transplantation, but rather that localization and the fate of transplanted cells is dramatically altered. These data demonstrate a novel role for PMNs in modulating cell migration, fate, and functional outcome of hCNS-SCns and suggest that distinct populations of immune cells infiltrating the spinal cord at different times postinjury could regulate donor cell efficacy. In particular, the observation that specific PMN depletion with anti-Ly6G treatment improved the recovery of function when combined with hNSC transplantation suggests that PMN depletion affected the in vivo activity of donor hNSCs in one or more of the following ways: (1) PMN depletion may have altered the state of the injured spinal cord, reducing damage or promoting a regenerative response, and changing the threshold required to for donor hNSCs to exert an effect on repair via a complementary or synergistic mechanism; (2) PMN depletion may have altered the migration 
and fate cues received by donor hNSCs in the injured spinal cord, restoring their potential to directly effect repair; or (3) a combination of these activities.

Although previous studies have not tested the role of PMNs in relation to cell transplantation, the effect of PMN infiltration on SCI pathogenesis and the state of the injured spinal cord is unclear. Several studies have suggested a detrimental role for PMNs in the postinjury spinal cord. PMN inhibition (up to several days post-SCI) with CXCR2 inhibitors (Gorio et al., 2007), elastase inhibitors (Tonai et al., 2001), phosphodiesterase inhibitors (Bao et al., 2011), and monoclonal anti-CD11 d antibodies (Saville et al., 2004) improved SCI and locomotor recovery. However, the neutralizing antibodies and inhibitors used were not PMN specific and also inhibit or deplete early infiltrating monocytes, therefore affecting monocyte-derived macrophages, which may promote tissue repair (David and Kroner, 2011; Saiwai et al., 2013).

Conversely, other studies have suggested that PMNs can promote regeneration and initiate inflammation-associated tissue repair. PMN depletion via anti-Gr-1 (clone RB6-8C5) antibody worsened injury and locomotor recovery at 28 or up to $42 \mathrm{~d}$ post-SCI (Stirling et al., 2009; Saiwai et al., 2013). Again, however, anti-Gr-1 acts on monocytes as well as PMNs; hence, these data could actually support a reparative role for monocytes after $\mathrm{SCI}$, as noted above. In parallel, PMNs express the regeneration promoting growth factor oncomodulin, and the specific immunodepletion of PMNs via anti-Ly6G (clone 1A8) treatment diminished oncomodulin levels and suppressed axon regeneration after inflammation-induced optic nerve injury (Kurimoto et al., 2013). However, anti-Ly6G antibody treatment did not alter either the lesion or locomotor recovery $42 \mathrm{~d}$ after contusion SCI in either previous reports (Saiwai et al., 2013) or in our current study, although it should be noted that there was a trend for a decrement in one CatWalk measure, regularity index, in vehicle + antiLy6G versus vehicle + IgG2a control at 12 weeks post-SCI. This observation could suggest a more complex role for PMN infiltration in long-term recovery after SCI. However, analysis of the RNA expression profile in naive, SCI + IgG-treated, and SCI + Ly6G-treated spinal cord 1 dpi demonstrated surprisingly few gene changes, which were principally focused on innate and adaptive immune responses at this early time point. Further studies of the peripheral and CNS immune response will be necessary to establish the relationships among PMN infiltration, activation/ infiltration of other immune populations, and the recovery of CNS function.

A second possibility is that PMN depletion altered the microenvironment of the injured spinal cord and thereby the migration and differentiation cues received by donor hNSCs, changing their capacity to directly effect repair. PMN infiltration post-SCI could modulate direct hNSC-mediated repair through several mechanisms. PMNs can synthesize cytokines/factors (e.g., TNF- $\alpha$, IL-6, ROS, complement proteins) that could affect donor hNSC fate and migration. Indeed, several studies have shown that the administration of TNF- $\alpha$ or IL- 6 , but not IL- $1 \beta$, increases $\mathrm{GFAP}^{+}$cell proliferation in culture (Selmaj et al., 1990; Pannu et al., 2005), suggesting that these PMN-synthesized cytokines could contribute to donor hNSC astrocytic fate and migration toward the injury epicenter after SCI. Furthermore, we have shown that PMN-generated complement components $\mathrm{Clq}$ and C3a are chemotactic for hNSCs, promote astroglial lineage selection, and impair oligodendroglial lineage selection in vitro, and that blockade of $\mathrm{Clq}$ and $\mathrm{C} 3 \mathrm{a}$ at the $\mathrm{SCI}$ epicenter reduces in vivo astroglial differentiation of acutely transplanted hNSCs (Hooshmand et al., 2017).

In accordance with these data, a principal change in donor hNSC behavior observed following PMN depletion was the reduction in recruitment of transplanted cells toward the injury epicenter and the decrease in astroglial fate in these cells. These data suggest that PMN-driven astrocytic fate and the migration of donor hNSCs toward the injury epicenter could contribute to the blockade of repair capacity, for example, by limiting the rostralcaudal "reach" of donor cells and diverting donor cells away from specific cell fates or phenotypes (e.g., oligodendroglia or formation of beneficial astrocytes). Regarding the latter, under normal physiological conditions astrocytes support neuronal growth. Moreover, delayed transplantation of astrocytes derived from BMP-stimulated embryonic glial-restricted precursors promotes behavioral recovery, axonal growth, and cell survival in rodent models of Parkinson's disease (Proschel et al., 2014) and SCI (Shih et al., 2014), suggesting that phenotype is a key variable in defining the effect of astroglial fate on repair and regeneration. In agreement with this concept, recent data suggest that phenotype may also play a role in the net effects of endogenous astroglial populations within the CNS (Hamby et al., 2012; Anderson and Maes 2014; Liddelow et al., 2017).

The data presented here are the first to demonstrate that the specific immunodepletion of an immune cell population can modulate the efficacy of a therapeutic cell population. However, it is important to note that the converse has been previously shown, suggesting that transplanted stem cell populations can affect the host inflammatory microenvironment to modulate repair and alter the survival/fate and recruitment of host cells. In particular, transplanted mesenchymal stromal/stem cells have been suggested to suppress the immune response through a number of direct cell-to-cell interactions and soluble factors (Bassi et al., 2011; Holubova et al., 2014; Kode et al., 2009). Furthermore, several studies have suggested an immunoprotective effect by engrafted undifferentiated neural precursor cells, either via apoptotic induction of blood-borne CNS-infiltrating encephalitogenic T cells or TL-R4 activation (Koutsoudaki et al., 2016). Although transplanted cells can potentially affect the host microenvironment (e.g., inflammation/astrogliosis), transplanted hCNS-SCns in our paradigm did not alter the level of PMNs or monocytes in the blood or spinal cord, as shown by flow cytometry.

It has frequently been assumed that acute transplantation of therapeutic stem cell populations would be problematic due to poor cell survival/engraftment (Okano 2002). In contrast, the acute versus delayed data presented here demonstrate equivalent engraftment 12 weeks after transplantation and suggest that the modulation of migration and lineage selection play a key role in the potential for repair. In this regard, PMN depletion or manipulation of other immune populations and inflammatory molecules may have clinical relevance as an approach to expand therapeutic window. Critically, differences in the immune response between rodents and humans may have a dramatic impact in considering the meaning of a therapeutic window in a clinical context. Although our study tested an early time window based on the timing of PMN infiltration in rodent SCI models (Beck et al., 2010), PMN infiltration in human SCI patients can persist for weeks, can be detected from months to years after SCI, and, as in rodent models, remains localized in the epicenter (Fleming et al., 2006). Future studies should consider strategies by which antiLy6G could be packaged into biodegradable materials [e.g., poly(lactic-co-glycolic acid)] for sustained local delivery at the lesion, as well as small-molecule inhibitors of PMN infiltration 
(e.g., sivelestat), which have been shown to be safely tolerated in the clinical setting (Ryugo et al., 2006; Aikawa et al., 2011). In particular, strategies that can avoid systemic PMN depletion or impairment of the overall systemic immune response would address key issues for polytrauma associated with SCI. In all, these data support the potential for clinical application of strategies to target the inflammatory microenvironment in combination with cell transplantation after SCI.

\section{References}

Aarum J, Sandberg K, Haeberlein SL, Persson MA (2003) Migration and differentiation of neural precursor cells can be directed by microglia. Proc Natl Acad Sci U S A 100:15983-15988. CrossRef Medline

Aikawa N, Ishizaka A, Hirasawa H, Shimazaki S, Yamamoto Y, Sugimoto H, Shinozaki M, Taenaka N, Endo S, Ikeda T, Kawasaki Y (2011) Reevaluation of the efficacy and safety of the neutrophil elastase inhibitor, Sivelestat, for the treatment of acute lung injury associated with systemic inflammatory response syndrome; a phase IV study. Pulm Pharmacol Ther 24:549-554. CrossRef Medline

Anderson AJ, Haus DL, Hooshmand MJ, Perez H, Sontag CJ, Cummings BJ (2011) Achieving stable human stem cell engraftment and survival in the CNS: is the future of regenerative medicine immunodeficient? Regen Med 6:367-406. CrossRef Medline

Anderson G, Maes M (2014) Reconceptualizing adult neurogenesis: role for sphingosine-1-phosphate and fibroblast growth factor- 1 in co-ordinating astrocyte-neuronal precursor interactions. CNS Neurol Disord Drug Targets 13:126-136. CrossRef Medline

Bao F, Fleming JC, Golshani R, Pearse DD, Kasabov L, Brown A, Weaver LC (2011) A selective phosphodiesterase-4 inhibitor reduces leukocyte infiltration, oxidative processes, and tissue damage after spinal cord injury. J Neurotrauma 28:1035-1049. CrossRef Medline

Bassi EJ, Aita CA, Câmara NO (2011) Immune regulatory properties of multipotent mesenchymal stromal cells: where do we stand? World J Stem Cells 3:1-8. CrossRef Medline

Beck KD, Nguyen HX, Galvan MD, Salazar DL, Woodruff TM, Anderson AJ (2010) Quantitative analysis of cellular inflammation after traumatic spinal cord injury: evidence for a multiphasic inflammatory response in the acute to chronic environment. Brain 133:433-447. CrossRef Medline

Bolger AM, Lohse M, Usadel B (2014) Trimmomatic: a flexible trimmer for Illumina sequence data. Bioinformatics 30:2114-2120. CrossRef Medline

Butovsky O, Ziv Y, Schwartz A, Landa G, Talpalar AE, Pluchino S, Martino G, Schwartz M (2006) Microglia activated by IL-4 or IFN-gamma differentially induce neurogenesis and oligodendrogenesis from adult stem/progenitor cells. Mol Cell Neurosci 31:149-160. CrossRef Medline

Cao QL, Zhang YP, Howard RM, Walters WM, Tsoulfas P, Whittemore SR (2001) Pluripotent stem cells engrafted into the normal or lesioned adult rat spinal cord are restricted to a glial lineage. Exp Neurol 167:48-58. CrossRef Medline

Cummings BJ, Uchida N, Tamaki SJ, Salazar DL, Hooshmand M, Summers $\mathrm{R}$, Gage FH, Anderson AJ (2005) Human neural stem cells differentiate and promote locomotor recovery in spinal cord-injured mice. Proc Natl Acad Sci U S A 102:14069-14074. CrossRef Medline

Daley JM, Thomay AA, Connolly MD, Reichner JS, Albina JE (2008) Use of Ly6G-specific monoclonal antibody to deplete neutrophils in mice. J Leukoc Biol 83:64-70. CrossRef Medline

David S, Kroner A (2011) Repertoire of microglial and macrophage responses after spinal cord injury. Nat Rev Neurosci 12:388-399. CrossRef Medline

de Castro RC Jr, Burns CL, McAdoo DJ, Romanic AM (2000) Metalloproteinase increases in the injured rat spinal cord. Neuroreport 11:35513554. CrossRef Medline

Dinkel K, Dhabhar FS, Sapolsky RM (2004) Neurotoxic effects of polymorphonuclear granulocytes on hippocampal primary cultures. Proc Natl Acad Sci U S A 101:331-336. CrossRef Medline

Fleming JC, Norenberg MD, Ramsay DA, Dekaban GA, Marcillo AE, Saenz AD, Pasquale-Styles M, Dietrich WD, Weaver LC (2006) The cellular inflammatory response in human spinal cords after injury. Brain 129: 3249-3269. CrossRef Medline

Gorio A, Madaschi L, Zadra G, Marfia G, Cavalieri B, Bertini R, Di Giulio AM (2007) Reparixin, an inhibitor of CXCR2 function, attenuates inflamma- tory responses and promotes recovery of function after traumatic lesion to the spinal cord. J Pharmacol Exp Ther 322:973-981. CrossRef Medline

Hamby ME, Coppola G, Ao Y, Geschwind DH, Khakh BS, Sofroniew MV (2012) Inflammatory mediators alter the astrocyte transcriptome and calcium signaling elicited by multiple G-protein-coupled receptors. J Neurosci 32:14489-14510. CrossRef Medline

Hamers FP, Koopmans GC, Joosten EA (2006) CatWalk-assisted gait analysis in the assessment of spinal cord injury. J Neurotrauma 23:537-548. CrossRef Medline

Holubova M, Lysak D, Vlas T, Vannucci L, Jindra P (2014) Expanded cryopreserved mesenchymal stromal cells as an optimal source for graftversus-host disease treatment. Biologicals 42:139-144. CrossRef Medline

Hooshmand MJ, Sontag CJ, Uchida N, Tamaki S, Anderson AJ, Cummings BJ (2009) Analysis of host-mediated repair mechanisms after human CNSstem cell transplantation for spinal cord injury: correlation of engraftment with recovery. PLoS One 4:e5871. CrossRef Medline

Hooshmand MJ, Nguyen HX, Piltti KM, Benavente F, Hong S, Flanagan L, Uchida N, Cummings BJ, Anderson AJ (2017) Neutrophils induce astroglial differentiation and migration of human neural stem cells via $\mathrm{Cl} \mathrm{C}$ and C3a synthesis. J Immunol 199:1069-1085. CrossRef Medline

Joelving FC, Billeskov R, Christensen JR, West M, Pakkenberg B (2006) Hippocampal neuron and glial cell numbers in Parkinson's disease-a stereological study. Hippocampus 16:826-833. CrossRef Medline

Jones TB, McDaniel EE, Popovich PG (2005) Inflammatory-mediated injury and repair in the traumatically injured spinal cord. Curr Pharm Des 11:1223-1236. CrossRef Medline

Karimi-Abdolrezaee S, Eftekharpour E, Wang J, Morshead CM, Fehlings MG (2006) Delayed transplantation of adult neural precursor cells promotes remyelination and functional neurological recovery after spinal cord injury. J Neurosci 26:3377-3389. CrossRef Medline

Keirstead HS, Nistor G, Bernal G, Totoiu M, Cloutier F, Sharp K, Steward O (2005) Human embryonic stem cell-derived oligodendrocyte progenitor cell transplants remyelinate and restore locomotion after spinal cord injury. J Neurosci 25:4694-4705. CrossRef Medline

Kigerl KA, McGaughy VM, Popovich PG (2006) Comparative analysis of lesion development and intraspinal inflammation in four strains of mice following spinal contusion injury. J Comp Neurol 494:578-594. CrossRef Medline

Kim MS, Pinto SM, Getnet D, Nirujogi RS, Manda SS, Chaerkady R, Madugundu AK, Kelkar DS, Isserlin R, Jain S, Thomas JK, Muthusamy B, LealRojas P, Kumar P, Sahasrabuddhe NA, Balakrishnan L, Advani J, George B, Renuse S, Selvan LD, et al (2014) A draft map of the human proteome. Nature 509:575-581. CrossRef Medline

Kode JA, Mukherjee S, Joglekar MV, Hardikar AA (2009) Mesenchymal stem cells: immunobiology and role in immunomodulation and tissue regeneration. Cytotherapy 11:377-391. CrossRef Medline

Kokaia Z, Martino G, Schwartz M, Lindvall O (2012) Cross-talk between neural stem cells and immune cells: the key to better brain repair? Nat Neurosci 15:1078-1087. CrossRef Medline

Koopmans GC, Deumens R, Honig WM, Hamers FP, Steinbusch HW, Joosten EA (2005) The assessment of locomotor function in spinal cord injured rats: the importance of objective analysis of coordination. J Neurotrauma 22:214-225. CrossRef Medline

Kopylova E, Noé L, Touzet H (2012) SortMeRNA: fast and accurate filtering of ribosomal RNAs in metatranscriptomic data. Bioinformatics 28:32113217. CrossRef Medline

Koutsoudaki PN, Papastefanaki F, Stamatakis A, Kouroupi G, Xingi E, Stylianopoulou F, Matsas R (2016) Neural stem/progenitor cells differentiate into oligodendrocytes, reduce inflammation, and ameliorate learning deficits after transplantation in a mouse model of traumatic brain injury. Glia 64:763-779. CrossRef Medline

Kurimoto T, Yin Y, Habboub G, Gilbert HY, Li Y, Nakao S, HafeziMoghadam A, Benowitz LI (2013) Neutrophils express oncomodulin and promote optic nerve regeneration. J Neurosci 33:14816-14824. CrossRef Medline

Lenzlinger PM, Morganti-Kossmann MC, Laurer HL, McIntosh TK (2001) The duality of the inflammatory response to traumatic brain injury. Mol Neurobiol 24:169-181. CrossRef Medline

Liao Y, Smyth GK, Shi W (2014) featureCounts: an efficient general purpose program for assigning sequence reads to genomic features. Bioinformatics 30:923-930. CrossRef Medline

Liddelow SA, Guttenplan KA, Clarke LE, Bennett FC, Bohlen CJ, Schirmer L, 
Bennett ML, Münch AE, Chung WS, Peterson TC, Wilton DK, Frouin A, Napier BA, Panicker N, Kumar M, Buckwalter MS, Rowitch DH, Dawson VL, Dawson TM, Stevens B, et al (2017) Neurotoxic reactive astrocytes are induced by activated microglia. Nature 541:481-487. CrossRef Medline

Liu S, Qu Y, Stewart TJ, Howard MJ, Chakrabortty S, Holekamp TF, McDonald JW (2000) Embryonic stem cells differentiate into oligodendrocytes and myelinate in culture and after spinal cord transplantation. Proc Natl Acad Sci U S A 97:6126-6131. CrossRef Medline

Luchetti S, Beck KD, Galvan MD, Silva R, Cummings BJ, Anderson AJ (2010) Comparison of immunopathology and locomotor recovery in C57BL/6, BUB/BnJ and NOD-SCID mice after contusion spinal cord injury. J Neurotrauma 27:411-421. CrossRef Medline

Martino G, Pluchino S (2006) The therapeutic potential of neural stem cells. Nat Rev Neurosci 7:395-406. CrossRef Medline

McCarthy DJ, Chen Y, Smyth GK (2012) Differential expression analysis of multifactor RNA-Seq experiments with respect to biological variation. Nucleic Acids Res 40:4288-4297. CrossRef Medline

Monje ML, Toda H, Palmer TD (2003) Inflammatory blockade restores adult hippocampal neurogenesis. Science 302:1760-1765. CrossRef Medline

Nakamura M, Okano H (2013) Cell transplantation therapies for spinal cord injury focusing on induced pluripotent stem cells. Cell Res 23:7080. CrossRef Medline

Nguyen HX, Beck KD, Anderson AJ (2011) Quantitative assessment of immune cells in the injured spinal cord tissue by flow cytometry: a novel use for a cell purification method. J Vis $\operatorname{Exp}(5): 2698$. CrossRef Medline

Okano H (2002) Neural stem cells: progression of basic research and perspective for clinical application. Keio J Med 51:115-128. CrossRef Medline

Pannu R, Singh AK, Singh I (2005) A novel role of lactosylceramide in the regulation of tumor necrosis factor alpha-mediated proliferation of rat primary astrocytes. Implications for astrogliosis following neurotrauma. J Biol Chem 280:13742-13751. CrossRef Medline

Parr AM, Kulbatski I, Zahir T, Wang X, Yue C, Keating A, Tator CH (2008) Transplanted adult spinal cord-derived neural stem/progenitor cells promote early functional recovery after rat spinal cord injury. Neuroscience 155:760-770. CrossRef Medline

Pathan M, Keerthikumar S, Ang CS, Gangoda L, Quek CY, Williamson NA, Mouradov D, Sieber OM, Simpson RJ, Salim A, Bacic A, Hill AF, Stroud DA, Ryan MT, Agbinya JI, Mariadason JM, Burgess AW, Mathivanan S (2015) FunRich: an open access standalone functional enrichment and interaction network analysis tool. Proteomics 15:2597-2601. CrossRef Medline

Popovich PG, Wei P, Stokes BT (1997) Cellular inflammatory response after spinal cord injury in Sprague-Dawley and Lewis rats. J Comp Neurol 377:443-464. CrossRef Medline

Popovich PG, Guan Z, Wei P, Huitinga I, van Rooijen N, Stokes BT (1999) Depletion of hematogenous macrophages promotes partial hindlimb recovery and neuroanatomical repair after experimental spinal cord injury. Exp Neurol 158:351-365. CrossRef Medline

Proschel C, Stripay JL, Shih CH, Munger JC, Noble MD (2014) Delayed transplantation of precursor cell-derived astrocytes provides multiple benefits in a rat model of Parkinsons. EMBO Mol Med 6:504-518. CrossRef Medline

Rapalino O, Lazarov-Spiegler O, Agranov E, Velan GJ, Yoles E, Fraidakis M, Solomon A, Gepstein R, Katz A, Belkin M, Hadani M, Schwartz M (1998) Implantation of stimulated homologous macrophages results in partial recovery of paraplegic rats. Nat Med 4:814-821. CrossRef Medline

Ryugo M, Sawa Y, Takano H, Matsumiya G, Iwai S, Ono M, Hata H, Yamau- chi T, Nishimura M, Fujino Y, Matsuda H (2006) Effect of a polymorphonuclear elastase inhibitor (sivelestat sodium) on acute lung injury after cardiopulmonary bypass: findings of a double-blind randomized study. Surg Today 36:321-326. CrossRef Medline

Saiwai H, Kumamaru H, Ohkawa Y, Kubota K, Kobayakawa K, Yamada H, Yokomizo T, Iwamoto Y, Okada S (2013) Ly6C+ Ly6G- myeloidderived suppressor cells play a critical role in the resolution of acute inflammation and the subsequent tissue repair process after spinal cord injury. J Neurochem 125:74-88. CrossRef Medline

Salazar DL, Uchida N, Hamers FP, Cummings BJ, Anderson AJ (2010) Human neural stem cells differentiate and promote locomotor recovery in an early chronic spinal cord injury NOD-scid mouse model. PLoS One 5:e12272. CrossRef Medline

Saville LR, Pospisil CH, Mawhinney LA, Bao F, Simedrea FC, Peters AA, O'Connell PJ, Weaver LC, Dekaban GA (2004) A monoclonal antibody to $\mathrm{CD} 11 \mathrm{~d}$ reduces the inflammatory infiltrate into the injured spinal cord: a potential neuroprotective treatment. J Neuroimmunol 156:42-57. CrossRef Medline

Schwartz M, Yoles E (2005) Macrophages and dendritic cells treatment of spinal cord injury: from the bench to the clinic. Acta Neurochir Suppl 93:147-150. CrossRef Medline

Selmaj KW, Farooq M, Norton WT, Raine CS, Brosnan CF (1990) Proliferation of astrocytes in vitro in response to cytokines. A primary role for tumor necrosis factor. J Immunol 144:129-135. Medline

Shihabuddin LS, Horner PJ, Ray J, Gage FH (2000) Adult spinal cord stem cells generate neurons after transplantation in the adult dentate gyrus. J Neurosci 20:8727-8735. Medline

Shih CH, Lacagnina M, Leuer-Bisciotti K, Pröschel C (2014) Astroglialderived periostin promotes axonal regeneration after spinal cord injury. J Neurosci 34:2438-2443. CrossRef Medline

Stirling DP, Liu S, Kubes P, Yong VW (2009) Depletion of Ly6G/Gr-1 leukocytes after spinal cord injury in mice alters wound healing and worsens neurological outcome. J Neurosci 29:753-764. CrossRef Medline

Subhash S, Kanduri C (2016) GeneSCF: a real-time based functional enrichment tool with support for multiple organisms. BMC Bioinformatics 17: 365. CrossRef Medline

Tamaki S, Eckert K, He D, Sutton R, Doshe M, Jain G, Tushinski R, Reitsma M, Harris B, Tsukamoto A, Gage F, Weissman I, Uchida N (2002) Engraftment of sorted/expanded human central nervous system stem cells from fetal brain. J Neurosci Res 69:976-986. CrossRef Medline

Tonai T, Shiba K, Taketani Y, Ohmoto Y, Murata K, Muraguchi M, Ohsaki H, Takeda E, Nishisho T (2001) A neutrophil elastase inhibitor (ONO5046) reduces neurologic damage after spinal cord injury in rats. J Neurochem 78:1064-1072. CrossRef Medline

Uchida N, Buck DW, He D, Reitsma MJ, Masek M, Phan TV, Tsukamoto AS, Gage FH, Weissman IL (2000) Direct isolation of human central nervous system stem cells. Proc Natl Acad Sci U S A 97:14720-14725. CrossRef Medline

Weaver KD, Branch CA, Hernandez L, Miller CH, Quattrocchi KB (2000) Effect of leukocyte-endothelial adhesion antagonism on neutrophil migration and neurologic outcome after cortical trauma. J Trauma 48:10811090. CrossRef Medline

Yagisawa M, Yuo A, Yonemaru M, Imajoh-Ohmi S, Kanegasaki S, Yazaki Y, Takaku F (1996) Superoxide release and NADPH oxidase components in mature human phagocytes: correlation between functional capacity and amount of functional proteins. Biochem Biophys Res Commun 228: 510-516. CrossRef Medline 